\title{
Determination of 25 Trace Element Concentrations in Biological Reference Materials by ICP-MS following Different Microwave-Assisted Acid Digestion Methods Based on Scaling Masses of Digested Samples
}

\author{
S. M. Enamorado-Báez, ${ }^{1,2}$ J. M. Abril, ${ }^{2}$ and J. M. Gómez-Guzmán ${ }^{3}$ \\ ${ }^{1}$ Centro Nacional de Aceleradores (CNA), Universidad de Sevilla, Thomas Alba Edison 7, 41092 Seville, Spain \\ ${ }^{2}$ Departamento de Fisica Aplicada I, E.T.S. de Ingenieria Agronomica, Universidad de Sevilla, Carretera Utrera km. 1, \\ 41013 Seville, Spain \\ ${ }^{3}$ Technische Universität München, Physics Department E12, James-Franck-Straße 1, 85748 Garching bei München, Germany
}

Correspondence should be addressed to J. M. Gómez-Guzmán; jose.gomez@ph.tum.de

Received 28 April 2013; Accepted 26 May 2013

Academic Editors: H. Alemu, G. Drochioiu, D. J. Fletouris, F. Kandemirli, A. Orte, and I. Zhukov

Copyright ( 2013 S. M. Enamorado-Báez et al. This is an open access article distributed under the Creative Commons Attribution License, which permits unrestricted use, distribution, and reproduction in any medium, provided the original work is properly cited.

\begin{abstract}
The use of normalized procedures designed for soil and sediment samples (like US-EPA 3051) to chemically prepare some kind of organic samples is a common practice in some laboratories. However, the performance of this method for other matrices has to be demonstrated. Three microwave-assisted digestion procedures with $0.5 \mathrm{~g}$ of sample and simplified reagents $\left(10 \mathrm{~mL} \mathrm{HNO}_{3}\right.$ alone and mixtures of $\mathrm{HNO}_{3} / \mathrm{HCl}$ - and $\mathrm{HNO}_{3} / \mathrm{H}_{2} \mathrm{O}_{2}$ procedures $\mathrm{A}, \mathrm{B}$, and $\mathrm{C}$, resp.) were compared for quantitative determination of 25 elements (Be, B, Al, Ti, V, Cr, Mn, Fe, Co, Ni, Cu, Zn, As, Se, Sr, Mo, Ag, Cd, Sb, Cs, Ba, Tl, Pb, Th and U) in three biological reference materials provided by NIST (mussel tissue (MT), tomato leaves (TL), and milk powder (MP)) by ICP-MS. From scaling masses (from 0.1 up to $0.9 \mathrm{~g}$ at $0.1 \mathrm{~g}$ interval) in procedure $\mathrm{A}$, a linear relationship among instrumental signal and mass of digested sample could be constructed at 99\% CL for most of the target analytes. The slope of this linear fit provided the estimation of sample concentration, while the ordinate in origin allowed the identification of matrix interferences which were absent in the reagent blank.
\end{abstract}

\section{Introduction}

Inductively coupled plasma mass spectrometry (ICP-MS) is a robust and widely used technique for multielemental and isotopic analysis of environmental materials [1-3] that has shown clear advantages when compared with other analytical techniques such as inductively coupled plasma atomic emission spectrometry (ICP-AES) [4-6], flame atomic absorption spectrometry (F-AAS), and electrothermal atomic absorption spectrometry (ET-AAS) $[7,8]$. The basic setup for ICP-MS analysis requires the sample introduction as a liquid solution and thus, for solid matrices, an acid digestion procedure becomes mandatory.

Sample digestion is mainly carried out by a fusion or a wet procedure based on an acid digestion with a heated mixture of mineral acids [2, 9-13]. In general, closed digestion systems are to be preferred to minimize possible contamination of the digest, increase reproducibility, and avoid losses of volatile elements [14-17]. Wet microwave digestion equipped with temperature and pressure control assisted by common mineral acids, such as nitric, sulphuric, perchloric and hydrochloric acids, is frequently used for sample digestion [18].

In order to dissolve the silicates and eliminate the effects of silica gel in environmental samples, hydrofluoric and orthoboric acids are usually used, although they can produce unsatisfactory recoveries in volatile elements $[19,20]$. A mixture of nitric acid and hydrogen peroxide is widely employed because they mineralise organic matter effectively and produce less spectral interference in ICP analyses [1]. Nitric acid has been reported to be strong enough to solubilize metals 
from fly ashes [21], from soils with organic carbon content up to $38 \%$ [22], and from plant materials for environmental monitoring [23]. However, in general, plant samples require a more complete decomposition procedure due to the presence of high organic and/or silicon contents [24].

The use of normalized procedures for soil and sediment samples to prepare some kind of organic sample is a common practice. The US-EPA 3051 [25] proposes to use a representative amount of sample of $0.5 \mathrm{~g}$ digested with $10 \mathrm{~mL}$ of concentrated nitric acid. For some cases this method also proposes the use of the same amount of sample digested in a mixture of $9 \mathrm{~mL}$ of concentrated nitric acid and $3 \mathrm{~mL}$ of concentrated hydrochloric acid. In the US-EPA 3052 [26] method, a representative sample of up to $0.5 \mathrm{~g}$ is digested in $9 \mathrm{~mL}$ of concentrated nitric acid, and usually $3 \mathrm{~mL}$ hydrofluoric acid, although the method has provisions for scaling the sample size up to a maximum of $1.0 \mathrm{~g}$ and enables the analyst to select other decomposition reagents. The use of hydrofluoric acid requires strict safety procedures, and it can damage the glass components during instrumental analysis if its excess was not previously removed from the samples. Apart from the normalized US-EPA methods, other digestion methods can be extracted from the specialized literature and used with particular samples [27]. Thus, in this work, we will study the performance of methods based on the use of just nitric acid compared with those using a combination of nitric acid and hydrochloric acid or hydrogen peroxide. These options were chosen on the basis of widespread usage and seemingly minimal contribution to ICP-MS spectral interferences.

In this work, we will be concerned with the analysis of biological samples with different characteristics to show the versatility of the procedures, although this is far away from being a universal procedure due to the limited number of certified materials used. The acid digestion methods proposed in the literature are used in the preparation of soil, sediments, and other complex matrices for a limited number of elements. The US-EPA methods pursuit the acid digestion and allow the quantification of up to 26 elements (Al, Sb, As, B, Ba, Be, Cd, $\mathrm{Ca}, \mathrm{Cr}, \mathrm{Co}, \mathrm{Cu}, \mathrm{Fe}, \mathrm{Pb}, \mathrm{Mg}, \mathrm{Mn}, \mathrm{Hg}, \mathrm{Mo}, \mathrm{Ni}, \mathrm{K}, \mathrm{Se}, \mathrm{Ag}, \mathrm{Na}, \mathrm{Sr}$, $\mathrm{Th}, \mathrm{V}$, and $\mathrm{Zn}$ ). The performance of this method for other analytes and/or matrices has to be demonstrated. Instrumental developments in both, ICP-MS and microwave digestion systems, and the need of limiting the use of hazardous acids lead to an increasing interest in the improvement and updating of sample digestion methods [1, 2, 28-32]. Until now, standard methods for soils and/or sediments have been directly applied to the preparation of organic samples. In this work, we will try to justify the use of those methods for organic samples and, depending on the results obtained, determine another alternative method which could give better results. For that reason, we have made a digestion procedure using only nitric acid (similar to the US-EPA 3051 method established for sediments, sludges, soils, and oils) but increasing the sample mass to acid volume ratio. Also, digestion procedures based on the use of a combination of nitric acid and hydrochloric acid or hydrogen peroxide have been checked.

The effect of microwave digestions with different reagents will be tested on 25 different elements determined through the ICP-MS technique in three different biological standard reference materials (SRMs) provided by the National Institute of Standards and Technology (NIST). The amount of sample will be scaled from 0.1 up to $0.9 \mathrm{~g}$ using just nitric acid. The study of the instrumental signal versus the sample mass will enable a quality test, when a good linearity is found, and will allow the determination of analyte concentration in the sample from the slope. Furthermore, an ordinate in origin different from zero at a fixed confidence level will serve to identify matrix effects noncompensated by a background subtraction based upon conventional digestion (reagents) blanks. Comparison between direct determination of concentrations based on dilution factors and the corresponding determined from the linear fit will serve to identify the mass distribution with unacceptable results. This, along with the study of relative uncertainties, will allow the construction of a figure of merit to find out the most suitable sample amount in the digest. Finally, a comparative study of three different digestion procedures applied to the SRM samples will be accomplished.

\section{Experimental}

2.1. Sample Materials and Reagents. In this work, the following biological standard reference materials (SRMs) provided by the National Institute of Standards and Technology (NIST) were used: SRM 1549 nonfat milk powder (referred hereafter as MP) [33], SRM 2976 mussel tissue (referred hereafter as MT) [34], and SRM 1573a tomato leaves (referred hereafter as TL) [35]. SRM 1549 was prepared by NIST to provide assistance in overcoming the difficulties in accurate trace and ultratrace levels analyses of food and other biological important materials (some of its certified elements have concentrations below $0.01 \mathrm{mg} \mathrm{kg}^{-1}$ ), and its certified major constituents with concentrations above 1\% (dry mass basis) are calcium, chlorine, phosphorus, and potassium. SRM 2976 were collected by the International Atomic Energy Agency (IAEA) from the Mediterranean coast of France as part of an effort to investigate metal speciation in the marine environment and its major constituents with concentrations above $1 \%$ (dry mass basis) are chlorine and sodium. Finally, SRM 1573a were obtained by the NIST from plants at the Horticultural Research Farm at Rock Springs, PA (USA). It was produced to evaluate the analyses of some elements in botanical materials and agricultural food products, and its certified major constituents with concentrations above $1 \%$ (dry mass basis) are calcium, nitrogen and potassium.

All reagents used for the microwave-assisted digestions, that is, hydrochloric acid $(36 \% \mathrm{HCl})$, nitric acid $\left(69 \% \mathrm{HNO}_{3}\right)$ and hydrogen peroxide $\left(30 \% \mathrm{H}_{2} \mathrm{O}_{2}\right)$, were of suprapur grade (Merck, Darmstadt, Germany). High-purity water $(18 \mathrm{M} \Omega \mathrm{cm}$ ) from a Milli-Q water purification system (Millipore, Bedford, USA) was used for dilution of the standards, for preparing samples throughout the chemical process, and for final rinsing of the acid-cleaned vessels, glasses, and plastic utensils.

Before use, all glass and plastic utensils were thoroughly acid cleaned and then rinsed with Milli-Q water. Moreover, prior to the use of the tetrafluoroethylene (PTFE-TFM) vessels, the following cleaning procedure was carried out: $10 \mathrm{~mL}$ of concentrated $\mathrm{HNO}_{3}$ was added to each vessel, and, once 
TABLE 1: Instrumental settings and calibration for ICP-MS.

\begin{tabular}{lc}
\hline ICP-MS instrument & \\
Forward power & $1300 \mathrm{~W}$ \\
Sampler and skimmer cones & Nickel \\
Argon flow rates & \\
$\quad$ Cool gas & $14.5 \mathrm{~L} \mathrm{~min}^{-1}$ \\
$\quad$ Auxiliary & $0.76 \mathrm{~L} \mathrm{~min}^{-1}$ \\
$\quad$ Nebuliser & $0.92 \mathrm{~L} \mathrm{~min}^{-1}$ \\
Acquisition parameters & \\
Ion monitoring mode & \\
$\quad$ Number of sweeps & \\
$\quad$ Channels per mass & 60 \\
$\quad$ Dwell time & 1 \\
$\quad$ Number of main runs & $10 \mathrm{~ms}^{-1}$ \\
Survey mode & 3 \\
$\quad$ Cannels per mass & \\
$\quad$ Sweeps & 10 \\
$\quad$ Dwell time & 10 \\
Internal standards & $0.6 \mathrm{~ms}$ \\
\hline
\end{tabular}

closed, the temperature was raised to $180^{\circ} \mathrm{C}$ within $15 \mathrm{~min}$ and held at this temperature for $10 \mathrm{~min}$. After cooling, the content of the vessels were discarded; PTFE-TFM vessels were soaked overnight with diluted $\mathrm{HNO}_{3}$ and then were rinsed with double deionised water.

The external calibration solutions must include known concentrations of each target analyte. They were prepared from standard certified elemental solutions (Cromlab) and Milli-Q water containing $1 \% \mathrm{HNO}_{3}$ to get a range of concentrations: $0.5,2.5,5.0,25.0,50.0$, and $250 \mu \mathrm{g} \mathrm{L}{ }^{-1}$ (for all elements except for Se, which were fivefold higher). A blank solution consisting in Milli-Q water containing $1 \% \mathrm{HNO}_{3}$ completed the calibration curve (counts versus $\mu \mathrm{g} \mathrm{L}^{-1}$ ) for each analyte.

The nonspectral matrix effects associated to the ICP-MS measurements were resolved by the addition of internal standards. The standard solution was prepared by diluting singleelemental stock solutions with Milli-Q water containing 1\% $\mathrm{HNO}_{3}$ up to get $50 \mu \mathrm{g} \mathrm{L}^{-1}$ of indium, terbium and bismuth, $500 \mu \mathrm{g} \mathrm{L}^{-1}$ scandium and $1000 \mu \mathrm{g} \mathrm{L}^{-1}$ lithium.

2.2. Analytical Instrumentation. An inductively coupled plasma mass spectrometry system Thermo Elemental ICP-MS X7 (Thermo Fisher, Cambridge, UK) with quadrupole mass analyzer, multichannel detector (Pulse Counting and Analog Methods), auto sampler ASX-500 (CETAC, Omaha, NE, USA), and software Plasma Lab version v4.5 was used for this work. The instrument, located at the Servicio de Investigación Agraria laboratory (University of Seville, Spain), was used with a concentric Meinhard type glass nebulizer, a silica impact bead spray chamber, cooled to $3^{\circ} \mathrm{C}$ by a Peltier cooler, and a standard silica torch. Standard nickel sample and skimmer cones were used. The internal standard solution was added online by a "Y" connection in the pipe where the sample is aspired by the peristaltic pump.
TABLE 2: Equations used for the correction of isobaric and polyatomic interferences ${ }^{\#}$.

\begin{tabular}{|c|c|c|}
\hline Element & $m / z$ & Correction equation \\
\hline V & 51 & $(1)^{51} \mathrm{~V}:-0.352^{52} \mathrm{Cr}-3.127^{53} \mathrm{Cr}$ \\
\hline As & 75 & (2) ${ }^{75}$ As: $-0.031^{82} \mathrm{Kr}-3.1322^{77} \mathrm{ArCl}$ \\
\hline Se & 82 & (3) ${ }^{82}$ Se: $-1.001^{83} \mathrm{Kr}$ \\
\hline $\mathrm{Cd}$ & 111 & (4) ${ }^{111} \mathrm{Cd}:-0.764^{106} \mathrm{Cd}-1.073^{108} \mathrm{Cd}$ \\
\hline $\mathrm{Pb}$ & 208 & $(5)^{208} \mathrm{~Pb}: 1.00^{206} \mathrm{~Pb}+1.00^{207} \mathrm{~Pb}$ \\
\hline
\end{tabular}

The ion optics were tuned to optimise the sensitivity of the signal at $m / z 9,59,115,137,140$, and 238 for a $100 \mathrm{mg} \mathrm{L}^{-1}$ beryllium, cobalt, indium, barium, cerium, and uranium solution, respectively, which was typically $10000-60000$ counts s $^{-1}$ in standard mode. The relative standard deviation of isotopes signals was less than $5 \%$. The oxide and double charged levels were both monitored to ensure that the ${ }^{140} \mathrm{Ce}^{+} /{ }^{140} \mathrm{Ce}^{16} \mathrm{O}^{+}$and ${ }^{137} \mathrm{Ba}^{+} /{ }^{137} \mathrm{Ba}^{++}$ratios did not exceed $2 \%$ and $5 \%$, respectively. Instrumental performance optimization, including nebulizer gas flow rate, RF power, and ion lens voltages, was performed and operational conditions are described in Table 1.

The US-EPA 200.8 method [36] is the routine analytical method implemented in our lab. In its original version, the method is applied for 21 elements, but in this work, we included $\mathrm{B}, \mathrm{Ti}, \mathrm{Fe}, \mathrm{Sr}$, and $\mathrm{Cs}$ and excluded mercury, since this last element requires a separate procedure due to its important memory effects. Thus, this was the list of 25 target analytes: $\mathrm{Be}, \mathrm{B}, \mathrm{Al}, \mathrm{Ti}, \mathrm{V}, \mathrm{Cr}, \mathrm{Mn}, \mathrm{Fe}, \mathrm{Co}, \mathrm{Ni}, \mathrm{Cu}, \mathrm{Zn}, \mathrm{As}, \mathrm{Se}$, $\mathrm{Sr}, \mathrm{Mo}, \mathrm{Ag}, \mathrm{Cd}, \mathrm{Sb}, \mathrm{Cs}, \mathrm{Ba}, \mathrm{Tl}, \mathrm{Pb}, \mathrm{Th}$, and $\mathrm{U}$.

Although there are recommended targets $m / z$ in the USEPA 200.8 method, usually several isotopes are monitored for each element. This provides helpful information for the analyst to properly interpret and quantify the acquired data. Thus, $48 \mathrm{~m} / z$ have been monitored in the main run mode, and spectra were acquired in survey mode for each measured sample. These spectra will serve to check interference effects. Finally, the undesirable effects of isobaric and polyatomic interferences were corrected using the interference correction equations given in Table 2 .

For closed-vessel digestions, a microwave system Multiwave 3000 (Anton Paar, Graz, Austria) with rotor HF100 and software version v1.52 was used. The system was equipped with 16 high-pressure PTFE-TFM vessels with an internal volume of $100 \mathrm{~mL}$ (maximum pressure and temperature of 40 bars and $240^{\circ} \mathrm{C}$, resp.).

2.3. Microwave-Assisted Digestion Procedures. Three digestion procedures using different reagents were tested for digestion of standard reference biological materials: procedure A, assisted by $\mathrm{HNO}_{3}$; procedure $\mathrm{B}$, assisted by $\mathrm{HNO}_{3}$ and $\mathrm{HCl}$; and procedure $\mathrm{C}$, assisted by $\mathrm{HNO}_{3}$ and $\mathrm{H}_{2} \mathrm{O}_{2}$. For the previously mentioned procedures, approximately $0.5 \mathrm{~g}$ of sample were weighted directly into the PTFE-TFM vessels, to which the reagents were added $\left(10 \mathrm{~mL} \mathrm{HNO}_{3}\right.$ for procedure $\mathrm{A}, 10 \mathrm{~mL} \mathrm{HNO}_{3}+3 \mathrm{~mL} \mathrm{HCl}$ for procedure $\mathrm{B}$, and $10 \mathrm{~mL} \mathrm{HNO}_{3}+3 \mathrm{~mL} \mathrm{H}_{2} \mathrm{O}_{2}$ for procedure $\mathrm{C}$ ) and the vessels 
were closed immediately. The operational conditions and the heating program used were carried out according to these conditions: a ramp time of $25 \mathrm{~min}$ to reach $200^{\circ} \mathrm{C}$ and a hold time of $25 \mathrm{~min}$ at $200^{\circ} \mathrm{C}$. After cooling the vessels to room temperature, they were vented and opened. In that moment, Milli-Q water was added to the vessels and they were closed and shaken thoroughly to dilute any possible rest of colloids attached in the vessels' walls. This process was repeated three times. The resultant mixture was filtered with a 20-25 $\mu \mathrm{m}$ diameter pore filter $110 \mathrm{~mm}$ diameter (Whatman) and diluted to $100 \mathrm{~mL}$ in a volumetric flask with Milli-Q water. To accomplish the TDS requirements for sample introduction in our ICP-MS, a further dilution of $1.2 \mathrm{~mL}(1.0 \mathrm{~mL}$ for procedure $\mathrm{C}$ ) of the previous digested solution to $10 \mathrm{~mL}$ of Milli-Q water with $1 \%$ suprapure $\mathrm{HNO}_{3}$ was needed. Triplicate samples of the three reference materials were prepared by each digestion method.

The digestion procedure $\mathrm{A}$ was then modified, keeping constant the acid volume $\left(10 \mathrm{~mL} \mathrm{HNO}_{3}\right)$ and scaling the sample mass from 0.1 up to $0.9 \mathrm{~g}$ at $0.1 \mathrm{~g}$ intervals. Triplicate samples of the three reference materials were prepared by this digestion method using the same microwave conditions previously described, and being then subject to the same dilution factor.

Matrix spike samples were prepared in duplicate following the US-EPA 200.8 procedure for the three biological matrices for a final extra concentration of $5 \mu \mathrm{g} \mathrm{L}^{-1}$ for all the analytes $\left(25 \mu \mathrm{g} \mathrm{L}^{-1}\right.$ for Se). Triplicate digested reagent blank solutions for each digestion procedure were analyzed for determination of the method detection limit (MDL) [2, 37]. These reagent blank solutions were ascribed for background correction in the postexperiment analysis.

2.4. Statistical Analysis. Each individual sample was measured with three main acquisition runs during the experiment, providing mean values and standard deviation. Results reported in this work will refer to the mean value and standard deviation of the three replicates of each organic matrix and digestion method.

The general linear model procedure in Statgraphics Plus 5.1 (StatPoint 2000) was used. This software was also used for regressions analyses.

\section{Results and Discussion}

3.1. Recovery of Internal Standard and Quality Controls. Recovery of internal standards decreased monotonically throughout the experiment up to $\sim 70 \%$ of their initial values for ${ }^{115} \mathrm{In},{ }^{159} \mathrm{~Tb}$, and ${ }^{209} \mathrm{Bi}$ and up to $76 \%$ for ${ }^{45} \mathrm{Sc}$, being this an usual behaviour. The recovery of ${ }^{6} \mathrm{Li}$ increased throughout the experiment to reach approximately a $140 \%$ of its initial value (in TL sample). This isotope can be naturally present in the samples, and it can be interfered by ${ }^{12} \mathrm{C}^{2+}$. Accordingly, ${ }^{6} \mathrm{Li}$ was removed as internal standard in the postexperiment analysis. All target analytes were ascribed to the interpolation mode except $\mathrm{Al}, \mathrm{Be}, \mathrm{B}$, and $\mathrm{Ti}$, which were directly ascribed to ${ }^{45} \mathrm{Sc}$.
The calibration curve for all the isotopes showed a good linearity over the whole range of concentrations, with correlation coefficients higher than 0.999 except for Fe and Al, which showed some deviations for low concentrations. Results for $\mathrm{Al}$ are reported, but they have to be handled carefully since some of the measured concentrations $\left(\sim 550 \mu \mathrm{g} \mathrm{L}^{-1}\right)$ were beyond the range of the calibration curve $\left(0.5-250 \mu \mathrm{g} \mathrm{L}^{-1}\right)$.

Quality control (QC) samples included external calibration verification (ICV), initial and continuous blank verification, and matrix spike samples (MXP). All target analytes passed all QC, but the $m / z=66(\mathrm{Zn})$ failed the ICV test for $5 \mu \mathrm{g} \mathrm{L}^{-1}$, although it showed a good behaviour for higher concentrations, in the range of the certified target values.

3.2. Reagent Blanks and Method Detection Limit (MDL). Detection limits for each digestion procedure (MDL) were determined from reagent blanks by using the US-EPA 200.8 definitions. Each reagent blank was prepared by using the same volume and acid combinations, and following the same experimental procedure used to prepare the real samples. Results are shown in Table 3. They are reported for the three digestion procedures which used $0.5 \mathrm{~g}$ of sample and referred to concentration in original sample $\left(\mathrm{mg} \mathrm{kg}^{-1}\right)$. For the variations made in procedure $\mathrm{A}$ with different sample amount, $m_{i}(\mathrm{~g})$, the corresponding MDLs can be obtained by correcting those from procedure A by a factor $0.5 / m_{i}$. The use of correction equations may affect the MDL, as shown in Table 3. The MDLs reported are about one order of magnitude higher than those reported by Sucharová and Suchara [1] because the dilution factor was also one order of magnitude higher in our case. For most of the elements, the choice of the digestion procedure had little influence on the MDL, in agreement with previous results [2].

When reagent blanks were treated as unknown samples with subtraction of the calibration blank, only Al (2.4$\left.5.5 \mu \mathrm{g} \mathrm{L}^{-1}\right)$ and $\mathrm{Cd}\left(\sim 0.03 \mu \mathrm{g} \mathrm{L}^{-1}\right)$ could be quantified over the instrument detection limits. The first one is an airborne pollutant, and the second one is likely linked to some crosscontamination coming from previous tracing studies carried out in our lab.

3.3. Procedure A with Scaling Masses: Linear Regression Meth$o d$. Concentrations in the digests were determined for each $\mathrm{m} / z$ ratio in each target analyte by using the corresponding calibration curve from calibration standards and the measured signal (after subtracting the corresponding reagent blank). Then, a mean value and a standard deviation of mean value were obtained from the three analytical replicates. Results were then plotted against the respective digested masses. Figures 1(a) and 1(b) show examples for a selected group of elements measured in MT. Data followed a linear relationship. Linear regression analysis provided the slope and ordinate in the origin (with their corresponding uncertainties) and the correlation coefficient. Concentrations below the detection limit in the digest were excluded from the analysis, applying the regression fit to the remaining data point.

Only in few cases the linear relationship did not hold (a confidence level below $90 \%$ was used as criteria for rejection), 
and the corresponding elements were discarded for quantification (see Tables 4(a), 4(b), and 4(c)). This usually happened for those analytes whose concentrations were below the detection limit for all or most of the masses (e.g., Ag or Cs in MT). The element ${ }^{47} \mathrm{Ti}$ was interfered by ${ }^{40} \mathrm{Ar}+{ }^{7} \mathrm{Li}$, being this last added as internal standard.

For most of the $m / z$ ratios, the linear relationship held at $99 \%$ CL (Table 4), with correlation coefficients over 0.97. Results are summarised in Tables 4(a), 4(b) and 4(c), where only one isotope (the one showing the best behaviour) has been selected for each target element.

There were two groups of elements regarding the ordinate in origin: those elements with an ordinate in origin compatible with zero value within 99\% CL and those ones with a value being different from zero at the same CL. Figures 1(a) and 1(b) show some examples for MT (noncompatible with zero and compatible with zero at $99 \%$ CL, resp.). The physical meaning of the slope is just the contribution to the instrumental signal (provided as $\mu \mathrm{g} \mathrm{L}^{-1}$ in the aspired solution) per unit mass of original organic sample. Thus, in both cases, the concentration of the target analyte in the organic sample can be obtained from the slope and the common dilution factor used for all samples (results are shown in Tables 4(a), 4(b), and 4(c), with associated uncertainties arising from the error in the slope). The comparison of these values with certified/reference ones is also provided in Tables 4(a), 4(b), and 4(c), and it will be discussed further.

The physical meaning of the ordinate in origin is just a contribution to the signal coming from matrix effects which are not present in the reagent blanks. Thus, these last include contributions from impurities in the reagent acids and water, as well as contamination throughout the analytical procedure. When a certain mass of organic sample is digested, even if the target analyte was absent, isobaric, polyatomic, and physical interferences could account to the background signal. It is worth to note that a direct quantification of the analyte using the total registered signal (corrected by reagent blank) and the dilution factor could misestimate the concentration value. A nonzero ordinate in origin could be likely lessened by using interference correction equations. Tables 4(a), 4(b), and 4(c) incorporate information of those elements showing nonzero ordinate in origin, and a brief discussion of the most relevant cases is presented in what follows.

Isotope ${ }^{51} \mathrm{~V}$ has a negative ordinate in origin when using the correction equation (Table 2) which becomes positive when omitting it. This is related with the nonfully adapted (to instrument and matrix) values of the parameters in the correction equation. The slope was not affected by the use of the correction equation. A similar situation was found for ${ }^{75}$ As. Isotope ${ }^{52} \mathrm{Cr}$ was used for element quantification (as recommended in the US-EPA 200.8 method), and its background was likely contributed by $\mathrm{C}$ and $\mathrm{Ca}$ in the matrix. Similarly, polyatomic interferences of ${ }^{1} \mathrm{H}+{ }^{59} \mathrm{Co}$ and ${ }^{1} \mathrm{H}+$ ${ }^{64} \mathrm{Zn}$ could contribute to the observed background in the ${ }^{60} \mathrm{Ni}$ and ${ }^{65} \mathrm{Cu}$ signals, respectively. Isotopes ${ }^{106} \mathrm{Cd}$ and ${ }^{108} \mathrm{Cd}$ showed background contribution likely linked to $\mathrm{Zn}$ in the sample, but ${ }^{111} \mathrm{Cd}$ was used for element quantification. Quantification of ${ }^{133} \mathrm{Cs}$ was difficult due to the low concentration
TABLE 3: Method detection limits (concentrations in $\mathrm{mg} \mathrm{kg}^{-1}$ ) determined for laboratory blank solutions.

\begin{tabular}{|c|c|c|c|c|c|}
\hline \multirow{2}{*}{ Element } & \multirow{2}{*}{$m / z$} & \multirow{2}{*}{ Equation $^{\#}$} & \multicolumn{3}{|c|}{ Procedure } \\
\hline & & & A & B & $\mathrm{C}$ \\
\hline $\mathrm{Be}$ & 9 & & 0.010 & 0.010 & 0.009 \\
\hline B & 11 & & 0.76 & 0.85 & 0.69 \\
\hline $\mathrm{Al}$ & 27 & & 2.9 & 4.7 & 2.0 \\
\hline $\mathrm{Ti}$ & 47 & & 2.5 & 1.4 & 3.5 \\
\hline V & 51 & (1) & 0.12 & 0.69 & 0.44 \\
\hline $\mathrm{V}$ & 51 & & 0.12 & N.R. & 0.91 \\
\hline $\mathrm{Cr}$ & 52 & & 0.055 & 1.9 & 0.047 \\
\hline $\mathrm{Mn}$ & 55 & & 0.033 & 0.11 & 0.039 \\
\hline $\mathrm{Fe}$ & 56 & & 10.2 & 9.8 & 8.6 \\
\hline Co & 59 & & 0.012 & 0.013 & 0.024 \\
\hline $\mathrm{Ni}$ & 60 & & 0.15 & 0.38 & 0.12 \\
\hline $\mathrm{Cu}$ & 63 & & 0.33 & 0.71 & 0.44 \\
\hline $\mathrm{Cu}$ & 65 & & 0.50 & 0.27 & 0.17 \\
\hline $\mathrm{Zn}$ & 66 & & 1.4 & 0.61 & 0.36 \\
\hline As & 75 & & 0.020 & N.R. & 0.20 \\
\hline As & 75 & (2) & 0.27 & 0.86 & 0.20 \\
\hline $\mathrm{Se}$ & 82 & (3) & 0.87 & 1.4 & 0.89 \\
\hline $\mathrm{Se}$ & 82 & & 0.88 & 0.89 & 0.97 \\
\hline $\mathrm{Sr}$ & 88 & & 0.045 & 0.014 & 0.028 \\
\hline Mo & 95 & & 0.26 & 1.13 & 0.32 \\
\hline $\mathrm{Ag}$ & 107 & & 0.081 & 0.013 & 0.009 \\
\hline $\mathrm{Cd}$ & 111 & (4) & 0.083 & 0.055 & 0.081 \\
\hline $\mathrm{Sb}$ & 123 & & 0.005 & 0.004 & 0.007 \\
\hline Cs & 133 & & 0.014 & 0.028 & 0.023 \\
\hline $\mathrm{Ba}$ & 137 & & 0.059 & 0.063 & 0.20 \\
\hline $\mathrm{Tl}$ & 205 & & 0.003 & 0.006 & 0.006 \\
\hline $\mathrm{Pb}$ & 208 & (5) & 0.024 & 0.017 & 0.090 \\
\hline Th & 232 & & 0.005 & 0.003 & 0.007 \\
\hline $\mathrm{U}$ & 238 & & 0.002 & N.Q. & 0.003 \\
\hline
\end{tabular}

Procedures: $\mathrm{A}\left(\mathrm{HNO}_{3}\right)$ and $\mathrm{B}\left(\mathrm{HNO}_{3}+\mathrm{HCl}\right)$ use dilution factors of $0.6 \mathrm{~g} \mathrm{~L}^{-1}$, while $0.5 \mathrm{~g} \mathrm{~L}^{-1}$ is applied for procedure $\mathrm{C}\left(\mathrm{HNO}_{3}+\mathrm{H}_{2} \mathrm{O}_{2}\right)$. In the three cases, $0.5 \mathrm{~g}$ of dry sample was digested. For the variations of method $\mathrm{A}$ with different amount of sample, $m_{i}(\mathrm{~g})$, the corresponding MDLs have to be corrected by a factor of $0.5 / m_{i}$.

${ }^{\#}$ Correction equations from Table 2.

N.R.: not recommended; N.Q.: not quantified.

and the interferences contributed by In, added as internal standard.

Concerning the determination of analyte concentrations from the slope, the values reported in Tables 4(a), 4(b) and $4(c)$, were in reasonable good agreement with the certified/reference ones, but in some cases significant statistical differences were found. When plotting the determined slope versus certificated/reference values of concentrations for all the analytes (not shown), a linear relationship holds at $99 \%$ CL $\left(R^{2}=0.991, n=38\right)$ with slope $0.886 \pm 0.014$. This last provides a gross estimation of the digestion yield, but elemental yields depend on the element geochemistry. Thus, incomplete recoveries in the digestions were found 


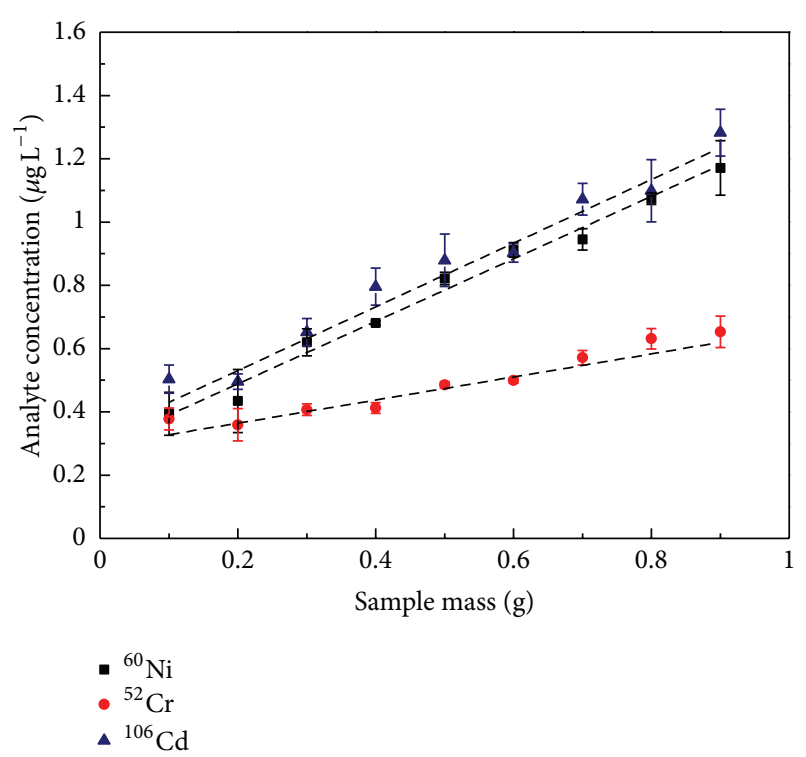

(a)

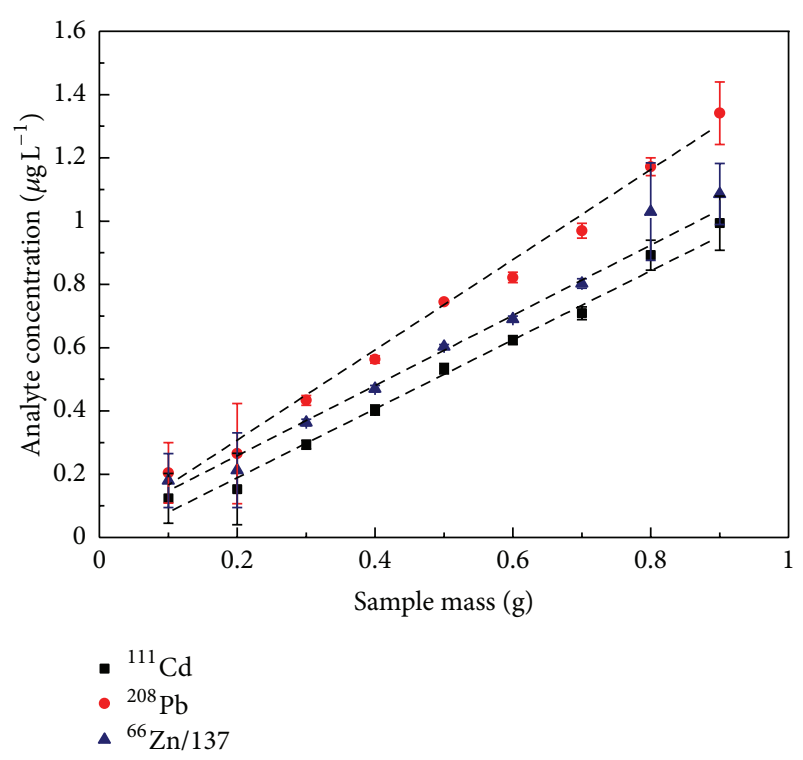

(b)

FIGURE 1: Examples of linear regression for a selected group of elements measured in MT matrix: (a) elements with noncompatible with zero ordinate in the origin at 99\% CL and (b) elements with compatible with zero ordinate in origin at 99\% CL. See text for explanation. Analyte concentrations are reported as a mean value and standard deviation from the three analytical replicates.

for $\mathrm{Fe}$ and $\mathrm{Sr}$ in $\mathrm{MT}$ and for $\mathrm{Al}, \mathrm{V}, \mathrm{Cr}, \mathrm{Fe}, \mathrm{Cu}$, and $\mathrm{Sb}$ in TL. Overestimations were identified for Se in MT (likely due to poor signal calibration in the low concentration range) and $\mathrm{Co}$ and $\mathrm{Ni}$ in TL. ${ }^{82} \mathrm{Se}$ recoveries could also be affected by ${ }^{81} \mathrm{Br}^{1} \mathrm{H}$ interference (MT has a $\mathrm{Br}$ concentration of $\left.329 \mathrm{mg} \mathrm{kg}^{-1}\right) .{ }^{59} \mathrm{Co}$ is also affected by an interference with $\mathrm{Ca}$ (formation of species ${ }^{43} \mathrm{Ca}^{16} \mathrm{O}$ and ${ }^{42} \mathrm{Ca}^{17} \mathrm{OH}$ ), present in TL in a percentage of 5.05\%. Arunachalam et al. [38] have also reported this overestimation in materials BCR CRM-141 and BCR CRM-142 digested by $\mathrm{HNO}_{3}(118 \%$ and $110 \%$, resp.) and by a mixture of $\mathrm{HNO}_{3}+\mathrm{HCl}+\mathrm{HF}(127 \%$ and $106 \%$, resp.).

\subsection{Procedure A with Scaling Masses: Direct Quantification} through the Dilution Factor. Concentrations of target analytes can be directly quantified for each amount of digested organic sample by using the corresponding dilution factors. This procedure has been applied in its standard version, that is, the recorded signal is corrected only by subtraction of the reagent blank and applying, when appropriate, the interference correction equations. Detailed results will not be reported here, but a general discussion is presented below.

The good linear relationship reported previously already ensures consistent results for the group of elements which are free of background contribution from matrix effect (those reported in Tables 4(a), 4(b), and 4(c) with compatible zero ordinate in origin and which will be referred hereafter as group "a"). For the complementary group (group "b", with background contribution), it is expected that a direct quantification will misestimate the values of the concentrations.

It has been found that digestion of low amount of sample leads to results with higher statistical dispersion. Results with very high associated uncertainties can pass a test of comparison against certified or reference values, but precision might be a target objective for the analyst. Thus, relative uncertainties have been estimated for each quantifiable analyte, and after, their averaged value and standard deviations were found for each digested mass. The resulting magnitude can be compared for the different masses ranging from 100 up to $900 \mathrm{mg}$. Results are shown in Figure 2 for MT and TL matrices. The smaller mass amounts (100 and $200 \mathrm{mg}$ ) produced overall higher relative uncertainties.

A statistical test to compare the mean values has been conducted to detect significant differences among the direct determination and those previously found from the slope. In this way, the effect of incomplete recovery during the digestion procedure can be discarded. The total number of failures found in MT and TL matrices has been quantified for each digested mass and separately for "a" and "b" class analytes. Results are reported in Figure 3, given as a percentage of the total number of analyte quantifications involved in each case. As expected, most of the direct determinations for class "b" analytes failed, with a trend of decreasing for increasing amounts of digested samples. The percentage of failures for "a" class analytes is small and concentrated around the low masses range. Actually, they are likely linked to the statistical variability previously reported in Figure 2.

Class "b" elements should not be directly quantified without an appropriate treatment of physical and isobaric interferences due to matrix effects. Thus, the selection of the most suitable amount of mass to be digested should fulfil two criteria: precision and accuracy. The first one can be quantified by the associated relative uncertainties; meanwhile, for the second criteria, the percentage of failures in comparison 
TABLE 4: (a) Measured (from slope) and certified/reference concentrations $\left(\mathrm{mg} \mathrm{kg}^{-1}\right.$ ) for the target analytes in the SRM 2976 mussel tissue. (b) Measured (from slope) and certified/reference concentrations ( $\mathrm{mg} \mathrm{kg}^{-1}$ ) for the target analytes in the SRM 1549 nonfat milk powder. (c) Measured (from slope) and certified/reference concentrations $\left(\mathrm{mg} \mathrm{kg}^{-1}\right)$ for the target analytes in the SRM 1573a tomato leaves.

(a)

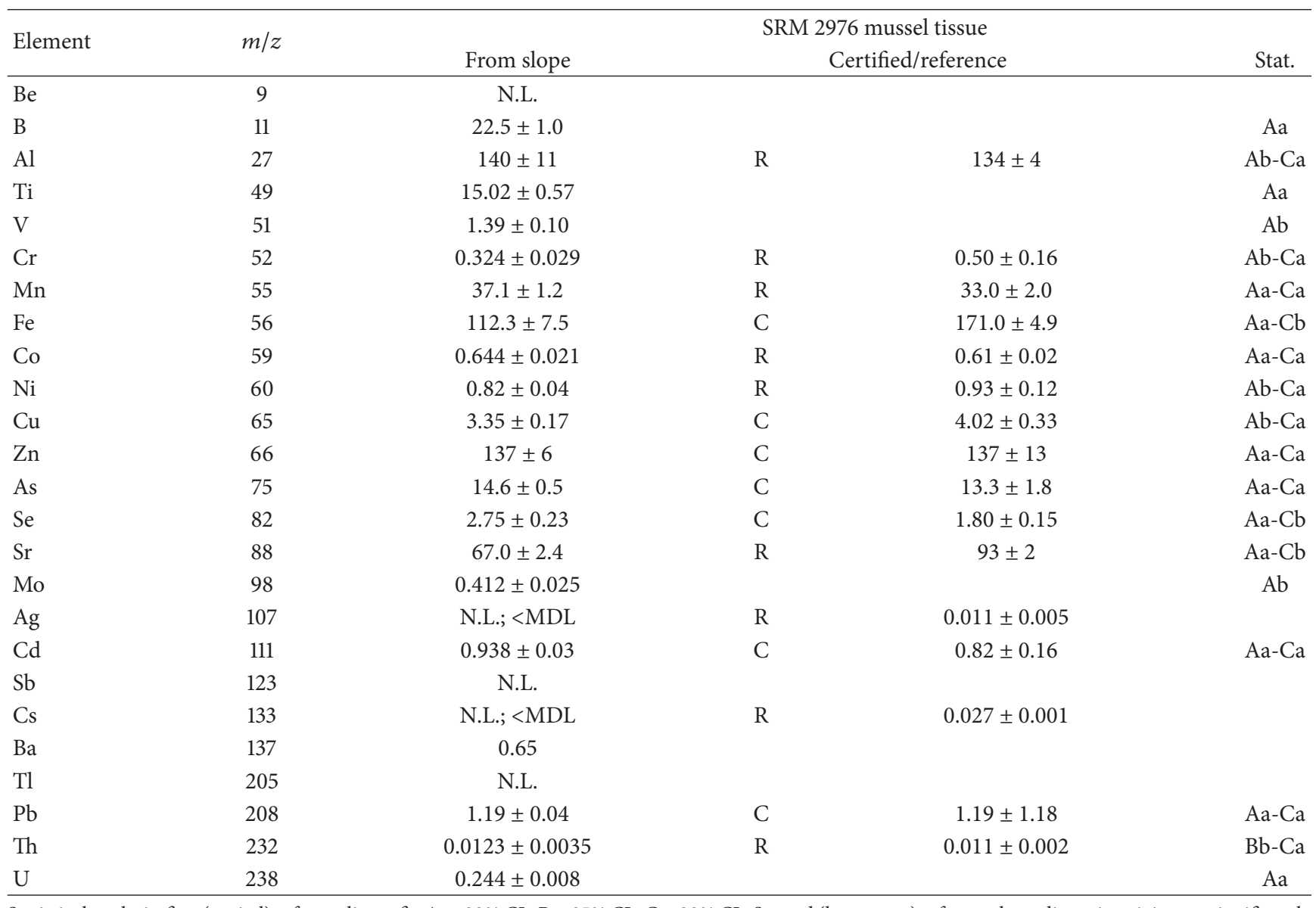

Statistical analysis: first (capital) refers to linear fit: A > 99\% CL, B > 95\% CL; C > 90\% CL. Second (lower case) refers to the ordinate in origin: not significantly different from zero at $99 \%$ CL; b, else. Third refers to the comparison between measured and certificated/reference values: Ca not statistically significant difference at $95 \% \mathrm{CL}, \mathrm{Cb}$, else. For those reference values without associated uncertainties, relative errors of $20 \%$ have been assumed.

N.L: nonpositive linear relationship; <MDL: below method detection limit;

R: reference value; $C$ : certified value.

(b)

\begin{tabular}{|c|c|c|c|c|c|}
\hline \multirow{2}{*}{ Element } & \multirow{2}{*}{$m / z$} & \multicolumn{4}{|c|}{ SRM 1549 nonfat milk powder } \\
\hline & & From slope & & reference & Stat. \\
\hline De & & N.L. & & & \\
\hline B & 11 & $2.8 \pm 0.7$ & & & $\mathrm{Ba}$ \\
\hline $\mathrm{Al}$ & 27 & N.L.; $<$ MDL & $\mathrm{R}$ & 2.0 & \\
\hline $\mathrm{Ti}$ & 49 & $2.63 \pm 0.17$ & & & $\mathrm{Aa}$ \\
\hline $\mathrm{V}$ & 51 & N.L. & & & \\
\hline $\mathrm{Cr}$ & 52 & N.L.; <MDL & $\mathrm{C}$ & $0.0026 \pm 0.0007$ & \\
\hline $\mathrm{Mn}$ & 55 & $0.254 \pm 0.010$ & $\mathrm{C}$ & $0.26 \pm 0.06$ & $\mathrm{Ab}-\mathrm{Ca}$ \\
\hline $\mathrm{Fe}$ & 56 & N.L.; <MDL & $\mathrm{C}$ & $1.78 \pm 0.1$ & \\
\hline Co & 59 & $<\mathrm{MDL}$ & $\mathrm{R}$ & 0.0041 & \\
\hline $\mathrm{Ni}$ & 60 & $0.308 \pm 0.027$ & & & $\mathrm{Ab}$ \\
\hline $\mathrm{Cu}$ & 65 & $0.71 \pm 0.29$ & $\mathrm{C}$ & $0.70 \pm 0.1$ & $\mathrm{Ca}-\mathrm{Ca}$ \\
\hline $\mathrm{Zn}$ & 66 & $43.9 \pm 1.4$ & $\mathrm{C}$ & $46.10 \pm 2.2$ & $\mathrm{Aa}-\mathrm{Ca}$ \\
\hline As & 75 & $<\mathrm{MDL}$ & $\mathrm{R}$ & 0.0019 & \\
\hline $\mathrm{Se}$ & 82 & $<\mathrm{MDL}$ & $\mathrm{C}$ & $0.110 \pm 0.010$ & \\
\hline
\end{tabular}


(b) Continued.

\begin{tabular}{|c|c|c|c|c|c|}
\hline \multirow{2}{*}{ Element } & \multirow{2}{*}{$m / z$} & \multicolumn{4}{|c|}{ SRM 1549 nonfat milk powder } \\
\hline & & From slope & & Certified/reference & Stat. \\
\hline $\mathrm{Sr}$ & 88 & $3.68 \pm 0.12$ & & & $\mathrm{Aa}$ \\
\hline Mo & 98 & $0.350 \pm 0.017$ & $\mathrm{R}$ & 0.34 & $\mathrm{Aa}-\mathrm{Ca}$ \\
\hline Ag & 107 & $<\mathrm{MDL}$ & $\mathrm{R}$ & $<0.0003$ & \\
\hline $\mathrm{Cd}$ & 111 & $<\mathrm{MDL}$ & $\mathrm{C}$ & $0.0005 \pm 0.0002$ & \\
\hline $\mathrm{Sb}$ & 123 & $<\mathrm{MDL}$ & $\mathrm{R}$ & 0.00027 & \\
\hline Cs & 133 & N.L. & & & \\
\hline $\mathrm{Ba}$ & 137 & $0.87 \pm 0.04$ & & & $\mathrm{Aa}$ \\
\hline $\mathrm{Tl}$ & 205 & N.L.; $<$ MDL & & & \\
\hline $\mathrm{Pb}$ & 208 & $<\mathrm{MDL}$ & $\mathrm{C}$ & $0.019 \pm 0.003$ & \\
\hline Th & 232 & N.L. & & & \\
\hline $\mathrm{U}$ & 238 & N.L. & & & \\
\hline
\end{tabular}

Statistical analysis: first (capital) refers to linear fit: A > 99\% CL; B > 95\% CL; C > 90\% CL. Second (lower case) refers to the ordinate in origin: not significantly different from zero at $99 \%$ CL; b, else. Third refers to the comparison between measured and certificated/reference values: Ca not statistically significant difference at 95\% CL, Cb, else. For those reference values without associated uncertainties, relative errors of $20 \%$ have been assumed.

N.L: nonpositive linear relationship; <MDL: below method detection limit;

R: reference value; C: certified value.

(c)

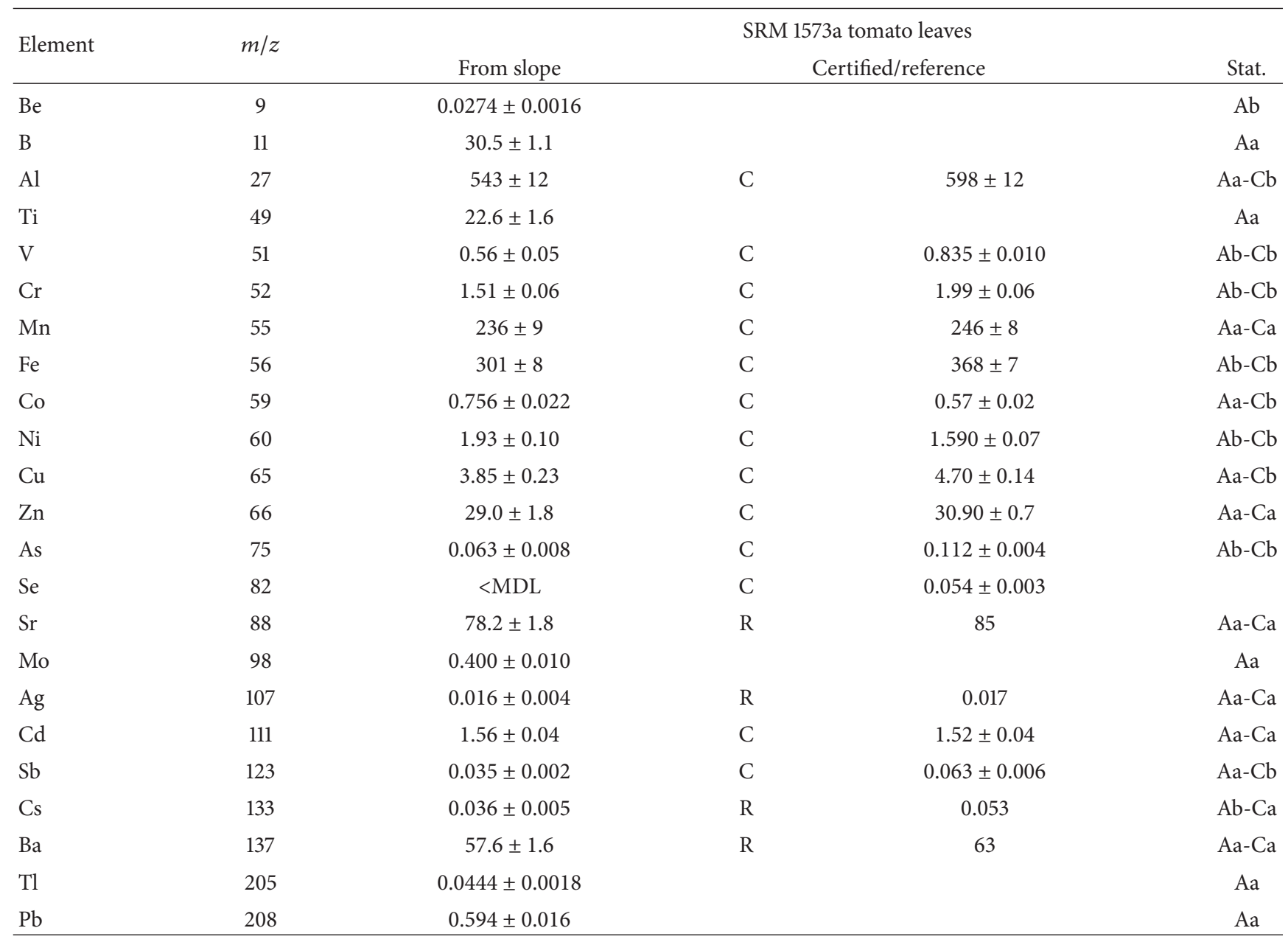


(c) Continued.

\begin{tabular}{lccccc}
\hline Element & $m / z$ & From slope & \multicolumn{2}{c}{ SRM 1573a tomato leaves } \\
& & $0.101 \pm 0.003$ & Certified/reference & S \\
\hline Th & 232 & $0.0298 \pm 0.0015$ & $\mathrm{R}$ & 0.120 & Aa-Ca \\
$\mathrm{U}$ & 238 & Aa-Ca \\
\hline
\end{tabular}

Statistical analysis: first (capital) refers to linear fit: A > 99\% CL; B > 95\% CL; C > 90\% CL. Second (lower case) refers to the ordinate in origin: not significantly different from zero at $99 \% \mathrm{CL}$; b, else. Third refers to the comparison between measured and certificated/reference values: Ca not statistically significant difference at $95 \% \mathrm{CL}, \mathrm{Cb}$, else. For those reference values without associated uncertainties, relative errors of $20 \%$ have been assumed.

N.L: nonpositive linear relationship; <MDL: below method detection limit;

$\mathrm{R}$ : reference value; $\mathrm{C}$ : certified value.

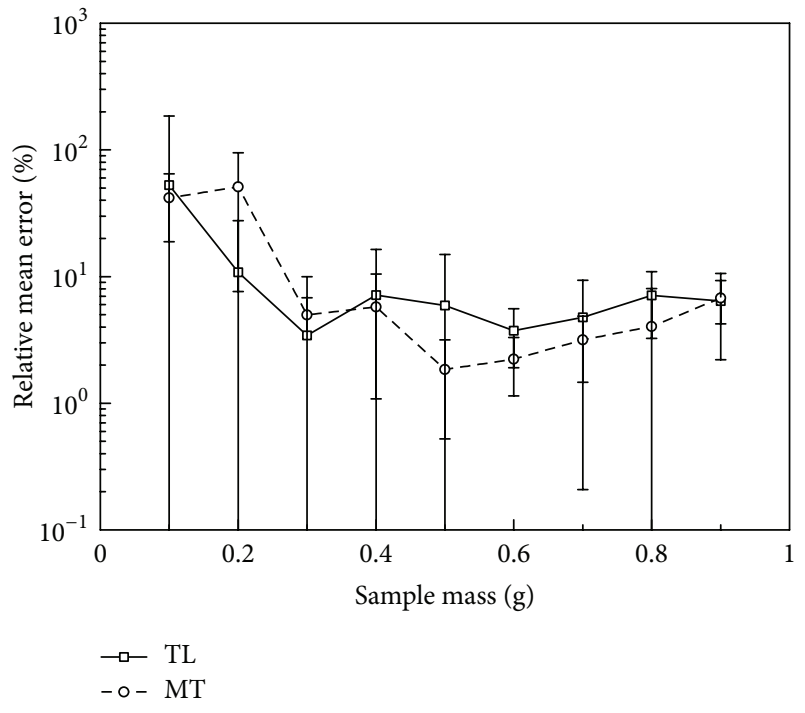

FIGURE 2: Statistical variability estimated for each quantifiable analyte in matrices TL and MT. The resulting magnitude can be compared for the different masses ranging from 100 up to $900 \mathrm{mg}$ (the smaller mass amounts produced overall higher relative uncertainties).

against reference values can serve as a reasonable quantification. Thus, the following "figure of merit" has been defined:

$$
\mathrm{FM}=f_{1}(100-\% \text { failures })+f_{2} \frac{\left\langle\varepsilon_{r}\right\rangle}{\varepsilon_{r}\left(m_{i}\right)},
$$

where $f_{1}$ and $f_{2}$ are user-defined weighting factors, $\varepsilon_{r}\left(m_{i}\right)$ is the averaged relative uncertainty found for mass $m_{i}$ (from Figure 2), and $\left\langle\varepsilon_{r}\right\rangle$ is the averaged value for all sample masses. Figure 3 shows this "figure of merit" for $f_{1}=f_{2}=50$. The best mass amount to be used in the digestion procedure is found to be around $600 \mathrm{mg}$, which corresponds with a sample mass to acid volume ratio of $60 \mathrm{mg} \mathrm{mL}^{-1}$. Slight changes in the values of the weighting factors $f_{1}$ and $f_{2}$ do not affect to the final result. This sample mass to acid volume ratio is similar to those reported elsewhere. For example, by Sucharová and Suchara [1] use a relation mass sample to acid ratio of 36 and $72 \mathrm{mg} \mathrm{mL}^{-1}$ (depending on the concentration of $\mathrm{Si}$ present in the samples) to determine the concentration of

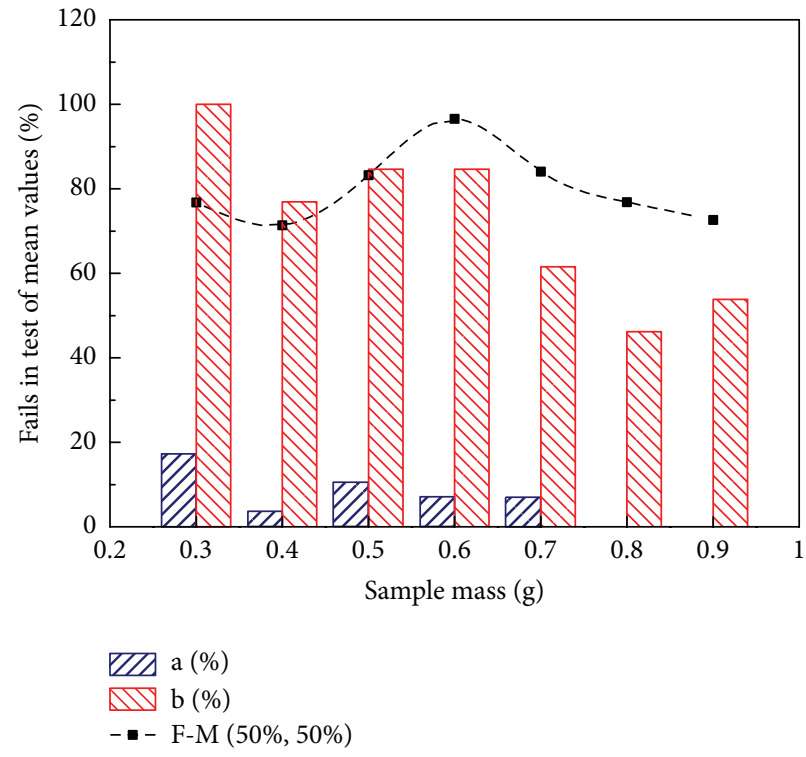

FIGURE 3: Percentages of direct determinations from the dilution factor with statistically significant differences (at 95\% CL) with respect to the value found from the slope (see Table 4 and Figures 1(a) and 1(b)) in MT and TL matrices). Classes "a" and "b" refer to isotopes with an ordinate in origin statistically nondifferent and statistically different from zero at 99\% CL, respectively (see text for explanation). The "figure of merit" (as defined in the text) pursuits the digested mass with the best compromise between precision and accuracy.

36 elements in different plant reference materials by ICP-MS after microwave digestions assisted by three different types of mixtures. González et al. [39] use a ratio of 67 to determine by ICP-OES the concentration of 7 elements in plant and animal samples after a microwave-assisted digestion with also nitric acid and hydrogen peroxide. Rodushkin et al. [40] reported a ratio of 50 for a microwave digestion with nitric acid and hydrogen peroxide prior to the determination of 16 elements in the certified reference material SRM 1547 (peach leaves) by ICP-AES, and ICP-SMS is reported. Finally, Sastre et al. [15] used a ratio of 66 in an acid digestion with nitric acid for the determination of $\mathrm{Cd}, \mathrm{Cu}, \mathrm{Pb}$, and $\mathrm{Zn}$ in a wide range of environmental samples (covering sediment, soil, sewage sludge, and plant matrices) by ICP-MS. 
3.5. Comparison among Digestion Procedures $A, B$, and $C$. Attending to previous results, the best procedure is the one using $600 \mathrm{mg}$ of sample and $10 \mathrm{~mL}$ of nitric acid. However, the US-EPA methods recommend $500 \mathrm{mg}$ of sample mass, so this amount was used to compare the digestion procedures with different mixtures of acids. $500 \mathrm{mg}$ of sample and dilution factors provided in the experimental section were used in all digestion procedures. Each target element was directly quantified from the measured signal after subtracting the corresponding reagent blank signal. Results are shown in Tables 5(a), 5(b), and 5(c), where the mean values and the standard deviation from three analytical replicates of each of the three matrices are reported. These data can be compared with certified/reference values and those obtained from the linear regression method (Tables 4(a), 4(b), and 4(c)). A Fisher's Least Significant Difference (LSD) test at 95\% CL has been conducted to discriminate the reported values for each analyte. Results are also shown in Tables 5(a), 5(b), and 5(c) and they will serve for the present discussion. It is worth to note that this statistical test is mediated by the effect of nonuniform uncertainties and by spurious background contributions by matrix effects which are not properly detected and treated by the quantification method.

Total recovery can be understood as the absence of statistically significant differences between digestion procedures and certified/reference values. As seen in Tables 5(a), 5(b) and 5 (c), this was found to be dependent on the matrix (the effect of the element concentration within the same matrix cannot be tested with our data).

There were not statistically significant differences among different digestion procedures at 95\% CL (including determinations from the slope) and between procedures and certified/reference values (when available) for the following set of elements (matrices are indicated as superindexes): $\mathrm{Mn}^{\mathrm{MP}}$, $\mathrm{Co}^{\mathrm{MT}}, \mathrm{Cu}^{\mathrm{MP}}, \mathrm{Zn}^{\mathrm{MT}, \mathrm{TL}}, \mathrm{As}^{\mathrm{MT}}, \mathrm{Sr}^{\mathrm{MP}, \mathrm{TL}}, \mathrm{Mo}^{\mathrm{MP}}, \mathrm{Ag}^{\mathrm{MT}, \mathrm{TL}}$, $\mathrm{Cd}^{\mathrm{MT}, \mathrm{TL}}, \mathrm{Ba}^{\mathrm{MT}, \mathrm{TL}}, \mathrm{Th}^{\mathrm{MT}}$, and $\mathrm{Pb}^{\mathrm{MT}}$. Nevertheless, most of these elements exhibited statistically significant differences in other matrices, and some of them were affected by spurious background contributions (see Tables 4(a), 4(b), and 4(c)). Thus, Mn showed apparently excellent results in MP matrix (in which it is affected by matrix background); meanwhile, the three digestion procedures overestimated its concentration in MT and underestimated it in TL matrix. Concentrations for the following set of elements were underestimated (when compared against certified/reference values) by all digestion procedures: $\mathrm{Fe}^{\mathrm{MT}, \mathrm{TL}}, \mathrm{Cu}^{\mathrm{MT}, \mathrm{TL}}, \mathrm{Zn}^{\mathrm{MP}}, \mathrm{Sr}^{\mathrm{MT}}$, and $\mathrm{Sb}^{\mathrm{TL}}$. Contrarily, concentrations were overestimated by the three procedures only for $\mathrm{Mn}^{\mathrm{MT}}$. Thus, Tables 5(a), 5(b), and 5(c) can provide so guidance for selecting the most appropriate procedure for any particular analyte depending on the matrix, but a general recommendation cannot be established for all three digestion procedures. Independent of the selected digestion procedure, the use of a sequence of digested masses should provide a more robust tool for quality control and absolute quantification with acceptable precision.

The digestion with $\mathrm{HNO}_{3}$ alone quantitatively extracted almost all the elements in the three SRMs. For the majority of elements analyzed in the samples, there was no clear improvement in the recovery when using $\mathrm{HNO}_{3}+\mathrm{HCl}$ or $\mathrm{HNO}_{3}+\mathrm{H}_{2} \mathrm{O}_{2}$ in the digestions compared to $\mathrm{HNO}_{3}$ alone. Incomplete recoveries were found for $\mathrm{Fe}, \mathrm{Sr}, \mathrm{Al}, \mathrm{V}, \mathrm{Cr}, \mathrm{Fe}, \mathrm{Cu}$, and $\mathrm{Sb}$, which could indicate a poor digestion of refractory $\mathrm{Si}$ likely affecting the recovery of silicon-bound elements. On the other hand, adding $\mathrm{HCl}$ to the $\mathrm{HNO}_{3}$ could carry out disadvantages because $\mathrm{Cl}^{-}$ion is retained in the final sample matrix and could create interferences in the determination of some elements, such as Va, Cr, and As [41], although this has not been noticed in this study.

\section{Conclusions}

Microwave-assisted digestion procedures with simplified reagents $\left(\mathrm{HNO}_{3}\right.$ alone and mixtures of $\mathrm{HNO}_{3} / \mathrm{HCl}$ and $\mathrm{HNO}_{3} /$ $\mathrm{H}_{2} \mathrm{O}_{2}$ ) were compared for quantitative determination of 25 elements (Be, B, Al, Ti, V, Cr, Mn, Fe, Co, Ni, Cu, Zn, As, Se, $\mathrm{Sr}, \mathrm{Mo}, \mathrm{Ag}, \mathrm{Cd}, \mathrm{Sb}, \mathrm{Cs}, \mathrm{Ba}, \mathrm{Tl}, \mathrm{Pb}, \mathrm{Th}$, and $\mathrm{U}$ ) in biological reference materials provided by NIST (mussel tissue, tomato leaves and milk powder) by ICP-MS.

The corresponding method detection limits were determined from reagent blanks, being comparable to those published in the scientific literature when the dilution factor is taken into account. For most of the elements, the choice of the digestion procedure had little influence on the MDL.

From scaling masses in procedure A, a linear relationship among instrumental signal (background corrected through reagent blank) and digested sample mass could be constructed at 99\% CL for most of the target analytes. No linear relationship was found for those present at very low concentrations (below their respective MDL) or interfered by internal standards. The slope of this linear fit provided, along with the applied dilution factor, the estimation of concentration in the sample, while the ordinate in origin allowed for the identification of matrix interferences which were absent in the reagent blank and which were not properly resolved by the implemented interference correction equations. When available, the so quantified concentrations were in good agreement with certified/reference values. This methodology provides a robust mean for evaluating both, the analyte recovery resulting from the digestion method and the reliability of the treatment of interferes. The best compromise between accuracy and precision was found when a sample amount of $600 \mathrm{mg}$ was used in the digestion, which corresponds to a sample mass to acid volume ratio of $60 \mathrm{mg} \mathrm{mL}^{-1}$.

The digestion with $\mathrm{HNO}_{3}$ alone (procedure A) quantitatively extracted almost all the elements in the three reference materials, although incomplete recoveries in the digestions were found for Fe and $\mathrm{Sr}$ in $\mathrm{MT}$ and for $\mathrm{Al}, \mathrm{V}, \mathrm{Cr}, \mathrm{Fe}, \mathrm{Cu}$, and $\mathrm{Sb}$ in TL, probably because these elements commonly occur as silicate compounds which are not solubilized efficiently using only $\mathrm{HNO}_{3}$.

There were not statistically significant differences among different digestion procedures for the following set of elements (matrices are indicated as superindexes): $\mathrm{Mn}^{\mathrm{MP}}, \mathrm{Co}^{\mathrm{MT}}$, $\mathrm{Cu}^{\mathrm{MP}}, \mathrm{Zn}^{\mathrm{MT}, \mathrm{TL}}, \mathrm{As}^{\mathrm{MT}}, \mathrm{Sr}^{\mathrm{MP}, \mathrm{TL}}, \mathrm{Mo}^{\mathrm{MP}}, \mathrm{Ag}^{\mathrm{MT}, \mathrm{TL}}, \mathrm{Cd}^{\mathrm{MT}, \mathrm{TL}}$, $\mathrm{Ba}^{\mathrm{MT}, \mathrm{TL}}$, $\mathrm{Th}^{\mathrm{MT}}$, and $\mathrm{Pb}^{\mathrm{MT}}$. Nevertheless, most of these 
TABLE 5: (a) Measured concentrations $\left(\mathrm{mg} \mathrm{kg}^{-1}\right)$ in SRM 2976 mussel tissue for target analytes using different digestion procedures. (b) Measured concentrations $\left(\mathrm{mg} \mathrm{kg}^{-1}\right.$ ) in SRM 1549 nonfat milk powder for target analytes using different digestion procedures. (c) Measured concentrations $\left(\mathrm{mg} \mathrm{kg}^{-1}\right)$ in SRM 1573a tomato leaves for target analytes using different digestion procedures.

(a)

\begin{tabular}{|c|c|c|c|c|c|}
\hline \multirow{2}{*}{ Element } & \multirow{2}{*}{$m / z$} & \multicolumn{4}{|c|}{ SRM 2976 mussel tissue } \\
\hline & & $\mathrm{A}$ & $\mathrm{B}$ & $\mathrm{C}$ & LSD at $95 \% \mathrm{CL}$ \\
\hline $\mathrm{Be}$ & 9 & $0.014 \pm 0.003$ & $<\mathrm{MDL}$ & $<\mathrm{MDL}$ & \\
\hline B & 11 & $20.5 \pm 0.6$ & $23.7 \pm 0.3$ & $22.7 \pm 2.0$ & $a b-a-b-a b-N$ \\
\hline $\mathrm{Al}$ & 27 & $184 \pm 9$ & $204.0 \pm 2.0$ & $133 \pm 14$ & $a-b-b-a-a$ \\
\hline $\mathrm{Ti}$ & 49 & $16.5 \pm 0.3$ & $28 \pm 3$ & $13.3 \pm 2.4$ & $a-a-b-a-N$ \\
\hline $\mathrm{V}$ & 51 & $2.24 \pm 0.17$ & N.Q. & $6.9 \pm 0.4$ & $\mathrm{a}-\mathrm{b}-\mathrm{N}-\mathrm{c}-\mathrm{N}$ \\
\hline $\mathrm{Cr}$ & 52 & $0.597 \pm 0.023$ & $1.74 \pm 0.05$ & $<\mathrm{MDL}$ & $a-b-c-N-b$ \\
\hline $\mathrm{Mn}$ & 55 & $38.7 \pm 0.3$ & $38.1 \pm 1.0$ & $38 \pm 3$ & b-b-b-b-a \\
\hline $\mathrm{Fe}$ & 56 & $110 \pm 4$ & $112 \pm 9$ & $110 \pm 10$ & $a-a-a-a-b$ \\
\hline Co & 59 & $0.663 \pm 0.009$ & $0.637 \pm 0.015$ & $0.63 \pm 0.06$ & $a-a-a-a-a$ \\
\hline $\mathrm{Ni}$ & 60 & $0.91 \pm 0.04$ & $1.02 \pm 0.27$ & $0.68 \pm 0.23$ & $a b-a b-b-a-a b$ \\
\hline $\mathrm{Cu}$ & 65 & $2.745 \pm 0.014$ & $2.920 \pm 0.028$ & $3.2 \pm 0.03$ & $c-a-a b-b c-d$ \\
\hline $\mathrm{Zn}$ & 66 & $138.7 \pm 2.8$ & $137 \pm 3$ & $133 \pm 11$ & $a-a-a-a-a$ \\
\hline As & 75 & $14.77 \pm 0.17$ & $12.8 \pm 0.3$ & $12.6 \pm 1.1$ & $a-a-a-a-a$ \\
\hline $\mathrm{Se}$ & 82 & $2.90 \pm 0.06$ & $1.6 \pm 0.5$ & $2.1 \pm 0.3$ & $b-b-a-a-a$ \\
\hline $\mathrm{Sr}$ & 88 & $69.3 \pm 0.5$ & $68.7 \pm 0.9$ & $68 \pm 6$ & $a-a-a-a-b$ \\
\hline Mo & 98 & $0.575 \pm 0.022$ & $0.486 \pm 0.021$ & $0.48 \pm 0.04$ & $a-c-b-b-N$ \\
\hline $\mathrm{Ag}$ & 107 & $0.020 \pm 0.004$ & $0.017 \pm 0.004$ & $0.014 \pm 0.012$ & $N-a-a-a-a$ \\
\hline $\mathrm{Cd}$ & 111 & $0.91 \pm 0.03$ & $0.90 \pm 0.07$ & $0.86 \pm 0.10$ & $a-a-a-a-a$ \\
\hline $\mathrm{Sb}$ & 123 & $0.0183 \pm 0.0021$ & $0.021 \pm 0.004$ & $0.0227 \pm 0.0020$ & $b-a-a-a-c$ \\
\hline Cs & 133 & $0.1687 \pm 0.0015$ & $0.33 \pm 0.05$ & $0.17 \pm 0.06$ & N-b-c-b-a \\
\hline $\mathrm{Ba}$ & 137 & $0.636 \pm 0.007$ & $0.59 \pm 0.04$ & $0.68 \pm 0.08$ & $a-a-a-a-N$ \\
\hline $\mathrm{Tl}$ & 205 & & & & \\
\hline $\mathrm{Pb}$ & 208 & $1.214 \pm 0.022$ & $1.11 \pm 0.0454$ & $1.15 \pm 0.10$ & $a-a-a-a-a$ \\
\hline Th & 232 & $0.0167 \pm 0.0015$ & $0.0140 \pm 0.0026$ & $0.015 \pm 0.004$ & $a-a-a-a-a$ \\
\hline $\mathrm{U}$ & 238 & $0.2430 \pm 0.0017$ & $0.243 \pm 0.0184$ & $0.237 \pm 0.018$ & $a-a-a-a-N$ \\
\hline
\end{tabular}

LSD test for the five independent determinations, ordered as follows: (1) from slope and scaling masses; (2) digestion method $\mathrm{A}\left(\mathrm{HNO}_{3}\right)$; (3) digestion method $\mathrm{B}\left(\mathrm{HNO}_{3}+\mathrm{HCl}\right) ;$ (4) digestion method $\mathrm{C}\left(\mathrm{HNO}_{3}+\mathrm{H}_{2} \mathrm{O}_{2}\right)$; and (5) certified/reference values; $\mathrm{N}$ means nonincluded; low case letters a, b, c, and d are classes ordered from lower to upper values; N.Q.: nonquantified; <MDL: below method detection limit.

Certified/reference values and obtained from slope and scaling masses are shown in Table 4(a).

(b)

\begin{tabular}{|c|c|c|c|c|c|}
\hline \multirow{2}{*}{ Element } & \multirow{2}{*}{$m / z$} & \multicolumn{4}{|c|}{ SRM 1549 milk powder } \\
\hline & & A & $\mathrm{B}$ & C & LSD at $95 \% \mathrm{CL}$ \\
\hline $\mathrm{Be}$ & 9 & & & & \\
\hline B & 11 & $3.2 \pm 0.6$ & $4.4 \pm 0.3$ & $4.0 \pm 1.0$ & $a-a b-b-a b-N$ \\
\hline $\mathrm{Al}$ & 27 & & & & \\
\hline $\mathrm{Ti}$ & 49 & & & & \\
\hline $\mathrm{V}$ & 51 & & & & \\
\hline $\mathrm{Cr}$ & 52 & & & & \\
\hline $\mathrm{Mn}$ & 55 & $0.203 \pm 0.013$ & $0.29 \pm 0.08$ & $0.23 \pm 0.14$ & $a-a-a-a-a$ \\
\hline $\mathrm{Fe}$ & 56 & & & & \\
\hline Co & 59 & & & & \\
\hline $\mathrm{Ni}$ & 60 & & & & \\
\hline $\mathrm{Cu}$ & 65 & $0.51 \pm 0.07$ & $0.41 \pm 0.13$ & $0.58 \pm 0.05$ & $a-a-a-a-a$ \\
\hline $\mathrm{Zn}$ & 66 & $42.7 \pm 2.7$ & $42.5 \pm 2.2$ & $42.0 \pm 2.4$ & $c-a b-a-b c-d$ \\
\hline As & 75 & & & & \\
\hline $\mathrm{Se}$ & 82 & & & & \\
\hline
\end{tabular}


(b) Continued.

\begin{tabular}{|c|c|c|c|c|c|}
\hline \multirow{2}{*}{ Element } & \multirow{2}{*}{$m / z$} & \multicolumn{4}{|c|}{ SRM 1549 milk powder } \\
\hline & & A & $\mathrm{B}$ & $\mathrm{C}$ & LSD at $95 \% \mathrm{CL}$ \\
\hline $\mathrm{Sr}$ & 88 & $3.51 \pm 0.17$ & $3.53 \pm 0.20$ & $3.49 \pm 0.25$ & $a-a-a-a-N$ \\
\hline Mo & 98 & $0.330 \pm 0.010$ & $0.310 \pm 0.027$ & $0.33 \pm 0.03$ & $a-a-a-a-a$ \\
\hline Ag & 107 & & & & \\
\hline $\mathrm{Cd}$ & 111 & & & & \\
\hline $\mathrm{Sb}$ & 123 & & & & \\
\hline Cs & 133 & & & & \\
\hline $\mathrm{Ba}$ & 137 & $0.81 \pm 0.05$ & $0.73 \pm 0.04$ & $0.80 \pm 0.06$ & b-ab-a-ab-N \\
\hline $\mathrm{Tl}$ & 205 & & & & \\
\hline $\mathrm{Pb}$ & 208 & & & & \\
\hline Th & 232 & & & & \\
\hline $\mathrm{U}$ & 238 & & & & \\
\hline
\end{tabular}

LSD test for the five independent determinations, ordered as follows: (1) from slope and scaling masses; (2) digestion method $\mathrm{A}\left(\mathrm{HNO}_{3}\right)$; (3) digestion method $\mathrm{B}\left(\mathrm{HNO}_{3}+\mathrm{HCl}\right) ;$ (4) digestion method $\mathrm{C}\left(\mathrm{HNO}_{3}+\mathrm{H}_{2} \mathrm{O}_{2}\right)$; and (5) certified/reference values; $\mathrm{N}$ means nonincluded; low case letters a, b, c, and d are classes ordered from lower to upper values; N.Q.: nonquantified; <MDL: below method detection limit.

Certified/reference values and obtained from slope and scaling masses are shown in Table 4(b).

(c)

\begin{tabular}{|c|c|c|c|c|c|}
\hline \multirow{2}{*}{ Element } & \multirow{2}{*}{$m / z$} & \multicolumn{4}{|c|}{ SRM 1573a tomato leaves } \\
\hline & & $\mathrm{A}$ & $\mathrm{B}$ & $\mathrm{C}$ & LSD at $95 \% \mathrm{CL}$ \\
\hline $\mathrm{Be}$ & 9 & $0.0127 \pm 0.0022$ & $<\mathrm{MDL}$ & $<\mathrm{MDL}$ & \\
\hline B & 11 & $30.2 \pm 0.4$ & $34.1 \pm 1.6$ & $33.8 \pm 1.4$ & $a-a-b-b-N$ \\
\hline $\mathrm{Al}$ & 27 & $567 \pm 23$ & $550 \pm 50$ & $557 \pm 14$ & $a-a b-a-a b-b$ \\
\hline $\mathrm{Ti}$ & 49 & $24.0 \pm 1.7$ & $31 \pm 3$ & $25 \pm 7$ & $a-a b-b-a b-N$ \\
\hline $\mathrm{V}$ & 51 & $0.79 \pm 0.04$ & N.Q. & N.Q & $a-b-N-N-b$ \\
\hline $\mathrm{Cr}$ & 52 & $1.65 \pm 0.10$ & $2.2 \pm 0.4$ & $0.87 \pm 0.06$ & b-bc-d-a-cd \\
\hline $\mathrm{Mn}$ & 55 & $219 \pm 6$ & $220 \pm 8$ & $226 \pm 7$ & $b c-a-a-a b-c$ \\
\hline $\mathrm{Fe}$ & 56 & $264 \pm 10$ & $281 \pm 13$ & $290 \pm 7$ & $c-a-a b-b c-d$ \\
\hline Co & 59 & $0.696 \pm 0.019$ & $0.708 \pm 0.028$ & $0.737 \pm 0.017$ & $c-b-b-b c-a$ \\
\hline $\mathrm{Ni}$ & 60 & $1.64 \pm 0.06$ & $1.78 \pm 0.25$ & $1.76 \pm 0.08$ & b-a-ab-ab-a \\
\hline $\mathrm{Cu}$ & 65 & $3.29 \pm 0.14$ & $3.24 \pm 0.16$ & $3.59 \pm 0.08$ & $c-a b-a-b c-d$ \\
\hline $\mathrm{Zn}$ & 66 & $25.9 \pm 0.9$ & $26.4 \pm 1.4$ & $27.4 \pm 1.7$ & $a-a-a-a-a$ \\
\hline As & 75 & $0.149 \pm 0.022$ & $0.78 \pm 0.14$ & $0.66 \pm 0.08$ & $b c-a-a b-a b-c$ \\
\hline $\mathrm{Se}$ & 82 & & & & \\
\hline $\mathrm{Sr}$ & 88 & $76.9 \pm 1.8$ & $75 \pm 3$ & $78.0 \pm 2.7$ & $a-a-a-a-a$ \\
\hline Mo & 98 & $0.362 \pm 0.015$ & $0.336 \pm 0.017$ & $0.377 \pm 0.011$ & $c-b-a-b c-N$ \\
\hline $\mathrm{Ag}$ & 107 & $0.029 \pm 0.018$ & $0.027 \pm 0.007$ & $0.015 \pm 0.004$ & $a-a-a-a-a$ \\
\hline $\mathrm{Cd}$ & 111 & $1.47 \pm 0.07$ & $1.51 \pm 0.07$ & $1.50 \pm 0.010$ & $a-a-a-a-a$ \\
\hline $\mathrm{Sb}$ & 123 & & & & \\
\hline Cs & 133 & $0.017 \pm 0.0020$ & $0.030 \pm 0.017$ & $0.020 \pm 0.013$ & $a b-a-a-a-b$ \\
\hline $\mathrm{Ba}$ & 137 & $55.3 \pm 2.0$ & $54.0 \pm 2.5$ & $56.7 \pm 1.4$ & $a-a-a-a-a$ \\
\hline $\mathrm{Tl}$ & 205 & $0.041 \pm 0.026$ & $0.040 \pm 0.004$ & $0.042 \pm 0.001$ & $a-a-a-a-N$ \\
\hline $\mathrm{Pb}$ & 208 & $0.548 \pm 0.0255$ & $0.49 \pm 0.0424$ & $0.539 \pm 0.003$ & $c-b c-a-a b-N$ \\
\hline
\end{tabular}


(c) Continued.

\begin{tabular}{lccccc}
\hline \multirow{2}{*}{ Element } & $m / z$ & \multicolumn{4}{c}{ SRM 1573a tomato leaves } \\
& & $\mathrm{A}$ & $\mathrm{B}$ & $\mathrm{C}$ & $\mathrm{LSD}$ at $95 \% \mathrm{CL}$ \\
\hline Th & 232 & $0.095 \pm 0.004$ & $0.088 \pm 0.0071$ & $0.100 \pm 0.007$ & ab-a-a-ab-b \\
$\mathrm{U}$ & 238 & $0.0293 \pm 0.0021$ & $0.0243 \pm 0.0031$ & $0.033 \pm 0.004$ & ab-ab-a-b-b \\
\hline
\end{tabular}

LSD test for the five independent determinations, ordered as follows: (1) from slope and scaling masses; (2) digestion method $\mathrm{A}\left(\mathrm{HNO}_{3}\right)$; (3) digestion method $\mathrm{B}\left(\mathrm{HNO}_{3}+\mathrm{HCl}\right) ;(4)$ digestion method $\mathrm{C}\left(\mathrm{HNO}_{3}+\mathrm{H}_{2} \mathrm{O}_{2}\right)$ and (5) certified/reference values; $\mathrm{N}$ means nonincluded; low case letters a, b, c and d are classes ordered from lower to upper values; N.Q.: nonquantified; <MDL: below method detection limit.

Certified/reference values and obtained from slope and scaling masses are shown in Table 4(c).

elements exhibited statistically significant differences in other matrices, and some of them were affected by spurious background contributions Concentrations were underestimated by the three digestion procedures for the following set of elements: $\mathrm{Fe}^{\mathrm{MT}, \mathrm{TL}}, \mathrm{Cu}^{\mathrm{MT}, \mathrm{TL}}, \mathrm{Zn}^{\mathrm{MP}}, \mathrm{Sr}^{\mathrm{MT}}$, and $\mathrm{Sb}^{\mathrm{TL}}$.

This illustrates the limitations of the assessment of different digestion methods throughout a direct quantification by the dilution factor, since it is mediated by a series of facts, as the nonuniform uncertainties, and by spurious background contributions by matrix effects which are not properly detected and treated by the quantification method.

\section{Conflict of Interests}

Some commercial identities are mentioned in this paper: (i) Merck, Darmstadt, Germany, (ii) Millipore, Bedford, USA, (iii) Cromlab, (iv) Thermo Fisher, Cambridge, UK, (v) CETAC, Omaha, NE, USA, and (vi) Anton Paar, Graz, Austria. None of the authors have any financial relation with any of those companies that could lead to a conflict of interests. The names of the companies have been written in the paper only as information for possible readers to know which kind of equipment has been used to get the results that we show.

\section{References}

[1] J. Sucharová and I. Suchara, "Determination of 36 elements in plant reference materials with different Si contents by inductively coupled plasma mass spectrometry: comparison of microwave digestions assisted by three types of digestion mixtures," Analytica Chimica Acta, vol. 576, no. 2, pp. 163-176, 2006.

[2] S. Ashoka, B. M. Peake, G. Bremner, K. J. Hageman, and M. R. Reid, "Comparison of digestion methods for ICP-MS determination of trace elements in fish tissues," Analytica Chimica Acta, vol. 653, no. 2, pp. 191-199, 2009.

[3] F. C. Bressy, G. B. Brito, I. S. Barbosa, L. S. G. Teixeira, and M. G. A. Korn, "Determination of trace element concentrations in tomato samples at different stages of maturation by ICP OES and ICP-MS following microwave-assisted digestion," Microchemical Journal, vol. 109, pp. 145-149, 2013.

[4] E. Paredes, M. S. Prats, S. E. Maestre, and J. L. Todolí, "Rapid analytical method for the determination of organic and inorganic species in tomato samples through HPLC-ICP-AES coupling," Food Chemistry, vol. 111, no. 2, pp. 469-475, 2008.
[5] W. P. C. dos Santos, V. Hatje, D. D. S. Santil, A. P. Fernandes, M. G. A. Korn, and M. M. de Souza, "Optimization of a centrifugation and ultrasound-assisted procedure for the determination of trace and major elements in marine invertebrates by ICP OES," Microchemical Journal, vol. 95, no. 2, pp. 169-173, 2010.

[6] A. Meche, M. C. Martins, B. E. S. N. Lofrano, C. J. Hardaway, M. Merchant, and L. Verdade, "Determination of heavy metals by inductively coupled plasma-optical emission spectrometry in fish from the Piracicaba River in Southern Brazil," Microchemical Journal, vol. 94, no. 2, pp. 171-174, 2010.

[7] A. Demirbas, "Oil, micronutrient and heavy metal contents of tomatoes," Food Chemistry, vol. 118, no. 3, pp. 504-507, 2010.

[8] L. S. Nunes, J. T. P. Barbosa, A. P. Fernandes et al., "Multielement determination of $\mathrm{Cu}, \mathrm{Fe}, \mathrm{Ni}$ and $\mathrm{Zn}$ content in vegetable oils samples by high-resolution continuum source atomic absorption spectrometry and microemulsion sample preparation," Food Chemistry, vol. 127, no. 2, pp. 780-783, 2011.

[9] M. Hoenig, H. Baeten, S. Vanhentenrijk, E. Vassileva, and P. Quevauviller, "Critical discussion on the need for an efficient mineralization procedure for the analysis of plant material by atomic spectrometric methods," Analytica Chimica Acta, vol. 358, no. 1, pp. 85-94, 1998.

[10] M. Canli and G. Atli, "The relationships between heavy metal $(\mathrm{Cd}, \mathrm{Cr}, \mathrm{Cu}, \mathrm{Fe}, \mathrm{Pb}, \mathrm{Zn})$ levels and the size of six Mediterranean fish species," Environmental Pollution, vol. 121, no. 1, pp. 129-136, 2003.

[11] H. Hornung, M. D. Krom, Y. Cohen, and M. Bernhard, "Trace metal content in deep-water sharks from the eastern Mediterranean Sea," Marine Biology, vol. 115, no. 2, pp. 331-338, 1993.

[12] A. Giguère, P. G. C. Campbell, L. Hare, D. G. McDonald, and J. B. Rasmussen, "Influence of lake chemistry and fish age on cadmium, copper, and zinc concentrations in various organs of indigenous yellow perch (Perca flavescens)," Canadian Journal of Fisheries and Aquatic Sciences, vol. 61, no. 9, pp. 1702-1716, 2004.

[13] H. Agemian, D. P. Sturtevant, and K. D. Austen, "Simultaneous acid extraction of six trace metals from fish tissue by hot-block digestion and determination by atomic-absorption spectrometry," Analyst, vol. 105, no. 1247, pp. 125-130, 1980.

[14] V. Sandroni and C. M. M. Smith, "Microwave digestion of sludge, soil and sediment samples for metal analysis by inductively coupled plasma-atomic emission spectrometry," Analytica Chimica Acta, vol. 468, no. 2, pp. 335-344, 2002.

[15] J. Sastre, A. Sahuquillo, M. Vidal, and G. Rauret, "Determination of $\mathrm{Cd}, \mathrm{Cu}, \mathrm{Pb}$ and $\mathrm{Zn}$ in environmental samples: microwave-assisted total digestion versus aqua regia and nitric acid extraction," Analytica Chimica Acta, vol. 462, no. 1, pp. 59-72, 2002. 
[16] H. Lachas, R. Richaud, A. A. Herod, D. R. Dugwell, R. Kandiyoti, and K. E. Jarvis, "Determination of 17 trace elements in coal and ash reference materials by ICP-MS applied to milligram sample sizes," Analyst, vol. 124, no. 2, pp. 177-184, 1999.

[17] L. García-Rico, R. E. Ramos-Ruiz, and L. Gutiérrez-Coronola, "Total metals in Cultivated oysters from the Northwest coast of Mexico determined by microwave digestion and atomic absorption spectrometry," The Journal of AOAC International, vol. 84, pp. 1909-1913, 2001.

[18] K. J. Lamble and S. J. Hill, "Microwave digestion procedures for environmental matrices," Analyst, vol. 123, no. 7, pp. 103R-133R, 1998.

[19] J. Ivanova, R. Djingova, S. Korhammer, and B. Markert, "On the microwave digestion of soils and sediments for determination of lanthanides and some toxic and essential elements by inductively coupled plasma source mass spectrometry," Talanta, vol. 54, no. 4, pp. 567-574, 2001.

[20] K. E. Jarvis, A. L. Gray, and R. Houk, Handbook of Inductively Coupled Plasma Mass Spectrometry, Blackie, London, UK, 1992.

[21] Z. Mester, M. Angelone, C. Brunori, C. Cremisini, H. Muntau, and R. Morabito, "Digestion methods for analysis of fly ash samples by atomic absorption spectrometry," Analytica Chimica Acta, vol. 395, no. 1-2, pp. 157-163, 1999.

[22] B. Xing and P. L. M. Veneman, "Microwave digestion for analysis of metals in soil," Communications in Soil Science and Plant Analysis, vol. 29, no. 7-8, pp. 923-930, 1998.

[23] N. N. Meeravali and S. J. Kumar, "Comparison of open microwave digestion and digestion by conventional heating for the determination of $\mathrm{Cd}, \mathrm{Cr}, \mathrm{Cu}$ and $\mathrm{Pb}$ in algae using transverse heated electrothermal atomic absorption spectrometry," Fresenius' Journal of Analytical Chemistry, vol. 366, no. 3, pp. 313-315, 2000.

[24] H. Polkowska-Motrenko, B. Danko, R. Dybczyński, A. KosterAmmerlaan, and P. Bode, "Effect of acid digestion method on cobalt determination in plant materials," Analytica Chimica Acta, vol. 408, no. 1-2, pp. 89-95, 2000.

[25] US-EPA Method 3051A, "Microwave assisted acid digestion of sediments, sludges, soils and oils," in Test Methods For Evaluating Solid Waste, US Environmental Protection Agency, Washington, DC, USA, 3rd edition, 2007.

[26] US-EPA Method 3052, "Microwave assisted acid digestion of siliceous and organically based matrices," in Test Methods For Evaluating Solid Waste, US Environmental Protection Agency, Washington, DC, USA, 3rd edition, 1995.

[27] H. M. Kingston and S. J. Haswell, Microwave-Enhanced Chemistry. Fundamentals, Sample Preparation and Applications, American Chemical Society, Washington, DC, USA, 1997.

[28] N. M. Hassan, P. E. Rasmussen, E. Dabek-Zlotorzynska, V. Celo, and H. Chen, "Analysis of environmental samples using microwave-assisted acid digestion and inductively coupled plasma mass spectrometry: maximizing total element recoveries," Water, Air, and Soil Pollution, vol. 178, no. 1-4, pp. 323-334, 2007.

[29] E. J. Llorent-Martínez, P. Ortega-Barrales, M. L. Fernández-de Córdova, A. Domínguez-Vidal, and A. Ruiz-Medina, "Investigation by ICP-MS of trace element levels in vegetable edible oils produced in Spain," Food Chemistry, vol. 127, pp. 1257-1262, 2001.

[30] H. Altundag and M. Tuzen, "Comparison of dry, wet and microwave digestion methods for the multi element determination in some dried fruit samples by ICP-OES," Food and Chemical Toxicology, vol. 49, no. 11, pp. 2800-2807, 2011.
[31] C. Yafa and J. G. Farmer, "A comparative study of acidextractable and total digestion methods for the determination of inorganic elements in peat material by inductively coupled plasma-optical emission spectrometry," Analytica Chimica Acta, vol. 557, no. 1-2, pp. 296-303, 2006.

[32] E. Marguí, I. Queralt, M. L. Carvalho, and M. Hidalgo, "Comparison of EDXRF and ICP-OES after microwave digestion for element determination in plant specimens from an abandoned mining area," Analytica Chimica Acta, vol. 549, no. 1-2, pp. 197204, 2005.

[33] NIST. National Institute of Standards and Technology, Certificate of Analysis, Standard Reference Material 1549 Non Fat Milk Powder, 2009.

[34] NIST. National Institute of Standards and Technology, Certificate of Analysis, Standard Reference Material 2976 Mussel Tissue, 2008.

[35] NIST. National Institute of Standards and Technology, Certificate of Analysis, Standard Reference Material 1573a Tomato Leaves, 1993.

[36] J. T. Creed, C. A. Brockhoff, and T. D. Martin, "US-EPA Method 200.8: determination of trace elements in waters and wastes by inductively coupled plasma-mass spectrometry," in Environmental Monitoring Systems Laboratory Office of Research and Development, Revision 5.4 EMMC Version, U.S. Environmental Protection Agency, Cincinnati, Ohio, USA, 1994.

[37] I. B. Brenner and B. Spence, "Determination of metals in environmental samples using the X series ICP-MS," in Instructions for Operation Based on US-EPA Method 200.8 Version 5.5, Version: 2-2, Thermo Electron Corporation, 2005.

[38] J. Arunachalam, C. Mohl, P. Ostapczuk, and H. Emons, "Multielement characterization of soil samples with ICP-MS for environmental studies," Fresenius' Journal of Analytical Chemistry, vol. 352, no. 6, pp. 577-581, 1995.

[39] M. H. Gonzalez, G. B. Souza, R. V. Oliveira, L. A. Forato, J. A. Nóbrega, and A. R. A. Nogueira, "Microwave-assisted digestion procedures for biological samples with diluted nitric acid: identification of reaction products," Talanta, vol. 79, no. 2, pp. 396401, 2009.

[40] I. Rodushkin, T. Ruth, and Å. Huhtasaari, "Comparison of two digestion methods for elemental determinations in plant material by ICP techniques," Analytica Chimica Acta, vol. 378, no. 1-3, pp. 191-200, 1999.

[41] R. Falciani, E. Novaro, M. Marchesini, and M. Gucciardi, "Multi-element analysis of soil and sediment by ICP-MS after a microwave assisted digestion method," Journal of analytical atomic spectrometry, vol. 15, no. 5, pp. 561-565, 2000. 

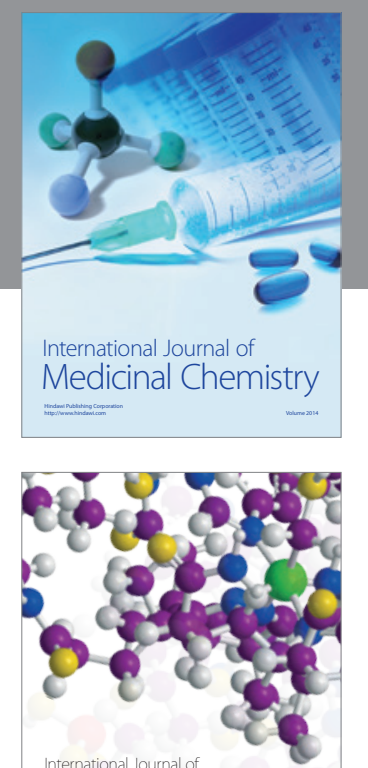

\section{Carbohydrate} Chemistry

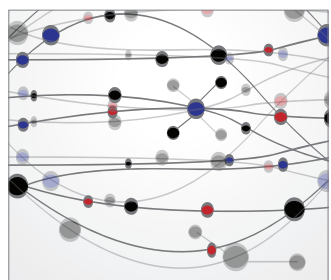

The Scientific World Journal
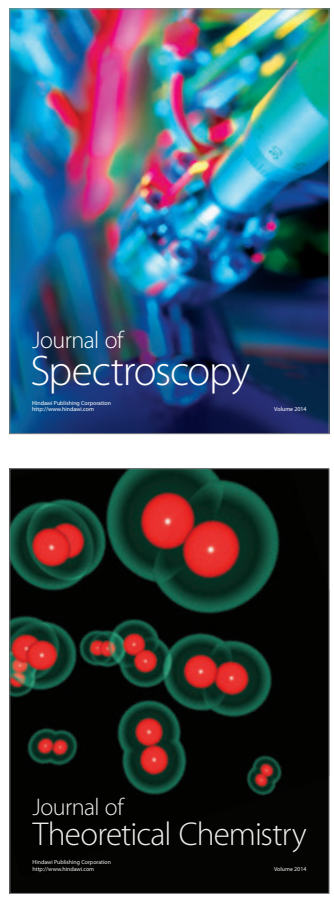
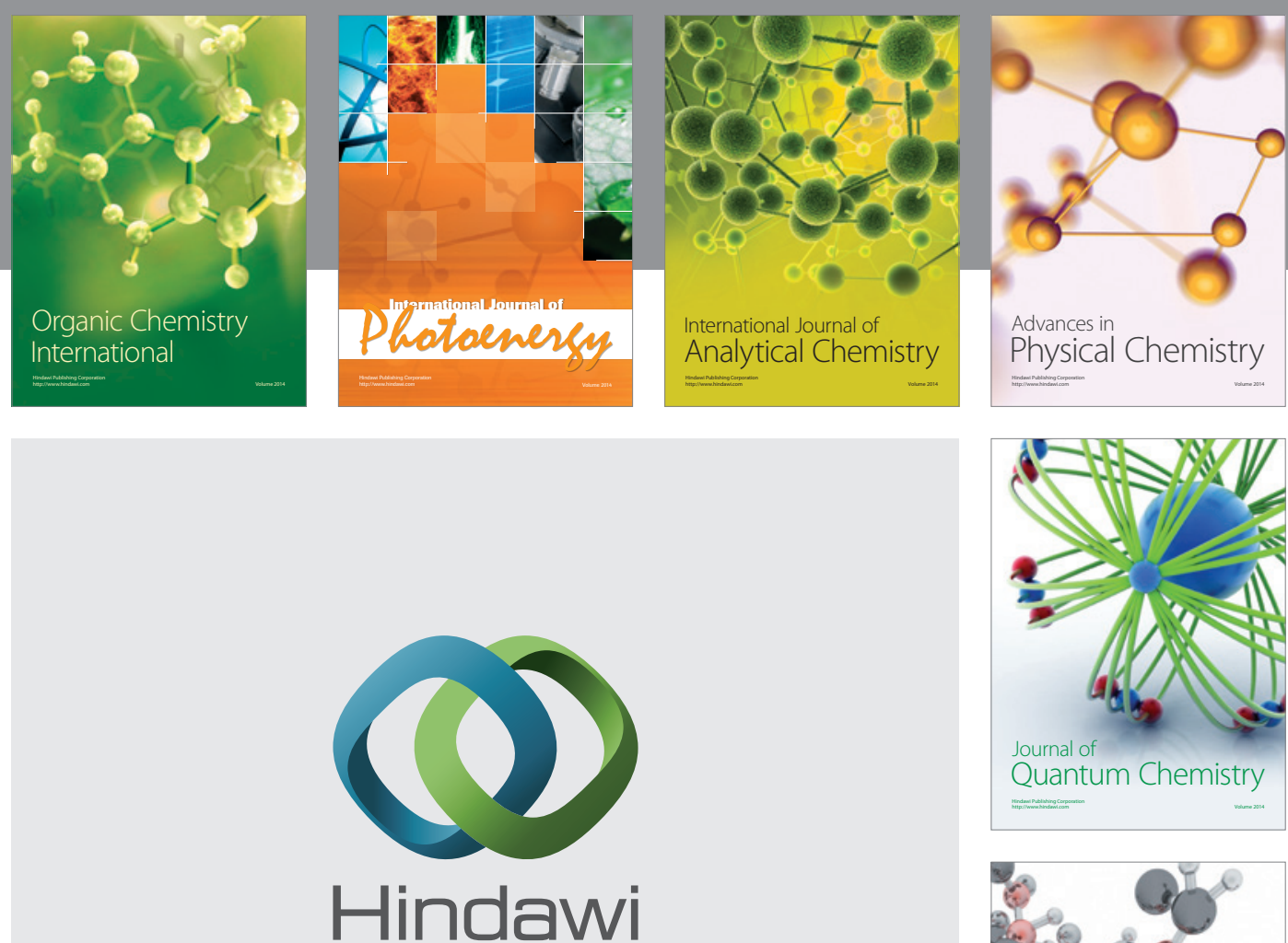

Submit your manuscripts at

http://www.hindawi.com

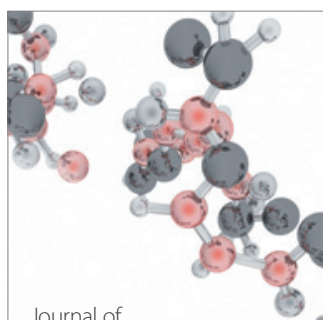

Analytical Methods

in Chemistry

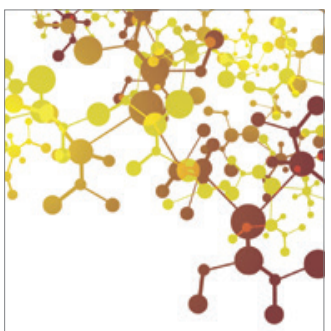

Journal of

Applied Chemistry

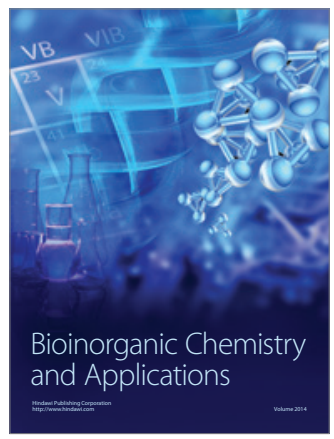

Inorganic Chemistry
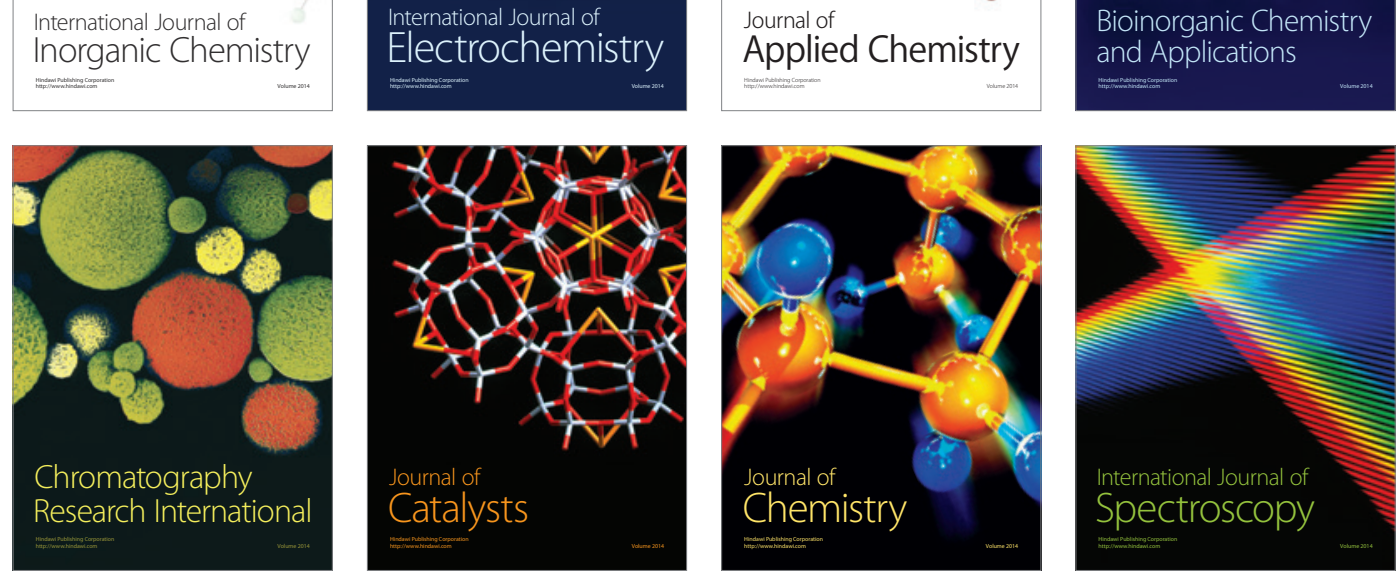